\title{
Optimization of Aeration Profiles in the Activated Sludge Process
}

\author{
Mustafa Cagdas Ozturk ${ }^{1}$, Fernando Martin Serrat ${ }^{1}$, Fouad Teymour* \\ Department of Chemical and Biological Engineering, Illinois Institute of Technology, 10 West 33rd Street, Suite \\ 127, Chicago, IL 60616, USA
}

\begin{abstract}
We show that the aeration rate in the activated sludge process, which is responsible for the greatest energy burden (up to 50\%) in wastewater treatment, can be reduced by more than $60 \%$, while preserving an effluent quality of less than $0.10 \mathrm{mg} / \mathrm{L}$ of ammonia and more than $8.5 \mathrm{mg} / \mathrm{L}$ of dissolved oxygen. An in-depth survey of the performances of different aeration profiles is given through utilization of an activated sludge tank model that was calibrated and validated with data from a real plant. First, the total rate of aeration is manipulated while employing equal rates of local aeration across the activated sludge tank. Then, scenarios with a nonuniform distribution of local aeration rates are investigated. For this purpose, a mixed-integer nonlinear programming (MINLP) problem was devised to minimize computational burden, which was solved using a genetic algorithm. Also, a similar MINLP problem was set to obtain aeration profiles with segments of equally-aerated zones in the tank, which can facilitate execution in real plants. Finally, all aeration profiles were challenged with a 2-day storm through dynamic simulations.
\end{abstract}

Keywords: activated sludge, aeration, optimization, wastewater, energy

\section{Introduction}

The energy expense of aeration process in activated sludge tanks has long been a major topic 3 in wastewater treatment research. Owing to the presence of multiple biological species that form

4 the activated sludge, the activated sludge process requires continuous aeration of the mixed liquor

5 to supply these microorganisms with sufficient dissolved oxygen, which enables the conversion of

\footnotetext{
${ }^{*}$ Corresponding author. Tel: +1 312567 8947; fax: +1 3125678874 .

Email addresses: mozturk@iit.edu (Mustafa Cagdas Ozturk), fmartins@hawk.iit.edu (Fernando Martin Serrat), teymour@iit.edu (Fouad Teymour)

${ }^{1} \mathrm{MCO}$ and FMS contributed equally. 
larger organic molecules in wastewater into smaller ones. In addition to its biological role, the forced aeration allows sufficient mixing in the activated sludge tank and contributes to the overall efficiency of the treatment process.

The consequences of insufficient aeration are typically encountered in the tank effluent as low dissolved oxygen and high ammonia concentrations, and usually lead to the violation of discharge permits enforced by local authorities. Typical discharge permits for the effluent quality of water reclamation plants (WRPs) are given in Table 1, as specified by the National Pollution Discharge Elimination System (NPDES). It should be noted that the effluent concentrations of WRPs are typically kept much lower than the values presented in Table 1. For the plant investigated in this study, which is introduced in the next section, the effluent ammonia concentration is usually less than $0.10 \mathrm{mg} / \mathrm{L}$, while the dissolved oxygen concentration is kept well above $6 \mathrm{mg} / \mathrm{L}$ under nominal operating conditions.

These values may seem to suggest that the wastewater treatment operation is carried out with high efficiency. On the other hand, very high aeration rates are utilized in order to maintain such an effluent quality, and this results in a big energy burden associated with the compression of air. Several sources report that about $40 \%$ to $60 \%$ of the energy expenditure of a WRP is associated with the aeration process $[1,2,3,4,5]$. In a recent study, we have shown that these aeration rates were in excess and could be decreased by $50 \%$ on average with minimal effect on the effluent quality [6]. As such, there are various studies on the minimization of the aeration in the activated sludge process with different process configurations, which usually include a control approach as well. For example, Chachuat and coworkers [7, 8] use a dynamic optimization approach to determine the optimal sequence of on/off periods for a small size alternating activated sludge (AAS) process. Fikar et. al. [9] employs a similar approach to the same process and account for the effect of diurnal variation in influent flow rate and composition. Åmand and Carlsson [10] utilize feedback control and optimization on a single-compartment process model, and discuss control strategies for plants where effluent constraints are defined over months or years. Piotrowski et. al. [11] consider an activated sludge tank consisting of one anaerobic, one anoxic, and four aerobic zones and use a model predictive control approach within a hierarchical control framework. 
Table 1: National Pollution Discharge Elimination System (NPDES) permits on plant effluent. ${ }^{\dagger}$

\begin{tabular}{ll}
\hline Pollutant & Discharge permit (mg/L) \\
\hline BOD $_{5}$ & $4-30 \mathrm{mg} / \mathrm{L}$ (monthly average) \\
Suspended solids & $5-30 \mathrm{mg} / \mathrm{L}$ (monthly average) \\
$\mathrm{NH}_{3}$-N & $2.5 \mathrm{mg} / \mathrm{L}$ (monthly average, April to October) \\
& $5.0 \mathrm{mg} / \mathrm{L}$ (daily limit, April to October) \\
& $4.0 \mathrm{mg} / \mathrm{L}$ (monthly average, November to March) \\
& $8.0 \mathrm{mg} / \mathrm{L}$ (daily limit, November to March) \\
& $\begin{array}{l}\text { Environmental Regulations for the State of Illinois. } \\
\text { http://www.ipcb.state.il.us/SLR/IPCBandIEPAEnvironmentalRegulations-Title35.aspx. }\end{array}$
\end{tabular}

Despite these efforts, application of advanced control strategies in WWTPs is very limited globally, due to the high complexity of the process and the cost of capital investment required $[12,13,14,15]$. In addition, there is skepticism against optimization of aeration in the activated sludge processes, which usually stems from the sensitivity of effluent quality to aeration and the necessity to protect against permit violations. In the absence of a clear insight toward the relation of process conditions and the required rate of aeration, it is usually preferred to keep the total aeration rates higher than necessary to avoid the effects of upstream disturbances, such as storms, temperature changes, or the quality and quantity of the influent wastewater.

Consequently, WWTPs need simpler approaches in the preliminary stages of minimization of aeration, which would ideally be performed with minimal investment and effort. Our work provides an option for such plants to conduct an offline optimization, which would yield an aeration profile that can be modified slightly to suit various conditions in the absence of automatic control. For this purpose, we use a realistic, validated aeration tank model, which consists of 48 aeration zones (modeled as CSTRs) and a settling tank, and employ an optimization approach to calculate optimal aeration profiles that would minimize the air usage and preserve the effluent quality. Considering the potential limitations for application, such as lack of automatic control valves for adjusting individual zones, we propose aeration profiles consisting of (i) uniform increase and decreases across the activated sludge tank, (ii) multiple uniformly-aerated zones (i.e. steps) that allow easy manipulation of the profile using a few header valves. In addition, we investigate the offline use of 
these profiles under excessive storm events to demonstrate their feasibility.

In our previous work [6], we have used bifurcation theory to investigate the steady state behavior of the process for different aeration rates and wastewater temperatures. However, this analysis was carried out with an aeration profile, in which the airflow rates were kept the same in all aerators across the tank, while the total airflow rate was manipulated. In this work, we show that it is possible to further minimize the total aeration rate of an activated sludge tank through utilization of a nonuniform distribution of local airflow rates, and an activated sludge tank model that was calibrated and validated with about 8 years of plant data from Stickney WRP, in Chicago, IL. Serving a population equivalent of 10.1 million and a capacity of 1.4 billion gallons per day (BGD), Stickney WRP is currently the largest WWTP in the world. The plant operates with strict daily and monthly effluent regulations, and the effluent dissolved oxygen is kept around $8.5 \mathrm{mg} / \mathrm{L}$ on average, thus making the optimization task more challenging but essential.

In the rest of this study, we first show that the aeration can be greatly reduced by adjusting the total rate of aeration, while keeping local aeration rates across the tank equal. Next, we allow different aeration rates across the tank and devise a mixed-integer nonlinear programming (MINLP) problem, which was solved using a Genetic Algorithm (GA) to show that further reduction in aeration is possible. Then, we test the robustness of the optimized aeration profiles toward excessive storm events. Finally, we demonstrate that simple structured (segmented) aeration profiles can be easily utilized in most WRPs for aeration minimization efforts without the need for automatic control valves.

\section{Water Reclamation Plant and Model}

\subsection{Stickney Water Reclamation Plant}

Throughout this study, we focus on the activated sludge tanks of the Stickney Water Reclamation Plant, which is located in west of Chicago, IL. The design capacity of Stickney WRP is 1.2 BGD, whereas the maximum capacity is $1.4 \mathrm{BGD}$, which makes it the largest WRP in the world. The plant is comprised of four secondary treatment batteries, each containing 8 activated sludge tanks and 24 clarifier tanks. In addition, each activated sludge tank has four passes.

Each activated sludge tank is $528 \mathrm{~m}$ long, $10.4 \mathrm{~m}$ wide and $4.6 \mathrm{~m}$ deep, and has a design capacity of 37.5 million gallons per day (MGD) $\left(141,953 \mathrm{~m}^{3} / \mathrm{d}\right)$ and a maximum capacity of 43.8 
Table 2: Influent composition and process parameters of the average day, calculated from 3002 days of plant data from Stickney WRP.

\begin{tabular}{cccc}
\hline Influent Parameter & Units & Value & Standard Deviation \\
\hline Water temperature & ${ }^{\circ} \mathrm{C}$ & 17.4 & \pm 5.72 \\
Influent flow rate & $\mathrm{MGD}$ & 21.24 & \pm 8.49 \\
Airflow rate & $\mathrm{MCFD}$ & 17.56 & \pm 4.61 \\
$\mathrm{BOD}_{5}$ & $\mathrm{mg} / \mathrm{L}$ & 115.4 & \pm 38.2 \\
$\mathrm{NH}_{3}-\mathrm{N}$ & $\mathrm{mg} / \mathrm{L}$ & 14.8 & \pm 4.28 \\
Total suspended solids & $\mathrm{mg} / \mathrm{L}$ & 111.6 & \pm 76.9 \\
MLSS & $\mathrm{mg} / \mathrm{L}$ & 3084.3 & \pm 615.96 \\
MLVSS & $\mathrm{mg} / \mathrm{L}$ & 2047.9 & \pm 388.62 \\
\hline
\end{tabular}




\subsection{Activated sludge tank model}

In order to carry out dynamic simulations and optimization, we use a previously developed model of the activated sludge tanks in Stickney WRP. The model, initially introduced by Ganesan [2], is a discretized plug flow reactor (PFR) model, and utilizes the Activated Sludge Model No. 1 (ASM1) $[16,17]$ for the reactions. As a result of its computational convenience, the discretized model, comprised of 48 continuous stirred tank reactors (CSTRs), was used for the simulations and optimization efforts (Figure 1). Equations for this model are given in Eqs. (1) and (2), whereas the state variables and model parameters are given in Table 2.2 .

$$
\begin{aligned}
\frac{d C_{i, j}}{d t} & =\frac{Q}{V}\left(C_{i-1, j}-C_{i, j}\right)+r_{i, j} \\
\frac{d S_{O, i}}{d t} & =\frac{Q}{V}\left(S_{O, i-1}-S_{O, i}\right)+\left(K_{L} a\right)_{i}\left(S_{O, i-1}^{S a t}-S_{O, i}\right)+r_{O, i}
\end{aligned}
$$

Note that with 10 species (denoted by $j$ ) and 48 CSTRs (denoted by $i$ ), the discretized model comprises 480 ordinary differential equations. The rate expressions $r_{i, j}$ and $r_{O, i}$ in Eqs. (1) and (2) were used as given in the ASM1 with the default parameter values. These rate expressions can be found in Table 4, whereas the default values for the kinetic parameters can be found elsewhere [17]. In addition, a semi-empirical expression for the liquid-side mass transfer coefficient for oxygen, $\left(K_{L} a\right)_{i}\left(d a y^{-1}\right)$, was obtained using the historical data from the plant. Using daily local aeration rate as the clustering variable and employing the $k$-means clustering method, the 3002 days of plant data was divided into 7 clusters. Next, a hundred days from each cluster were chosen for simulation and all $\left(K_{L} a\right)_{i}$ values across the tank (which are equal by default) were manipulated (while keeping them equal) to match the reported mixed liquor suspended solids (MLSS) concentration for that day. Upon matching the MLSS concentration reported in the plant data, the current $\left(K_{L} a\right)_{i}$ value was associated with the reported local aeration rate. Then, these values were averaged over the hundred days for each cluster and an equation in the form of Eq. (3), where $a_{i}\left(\mathrm{~m}^{3} /\right.$ day) corresponds to the local aeration rate, was fitted to this data using nonlinear regression.

$$
\left(K_{L} a\right)_{i}=\frac{1468.62 a_{i}^{3.41}}{3.84 \times 10^{12}+a_{i}^{3.41}}
$$

The model developed by Ganesan [2] was calibrated and validated using 3002 days of daily average data from Stickney WRP between the years 2001 and 2009. The validation was carried 
Table 3: Model variables and parameters.

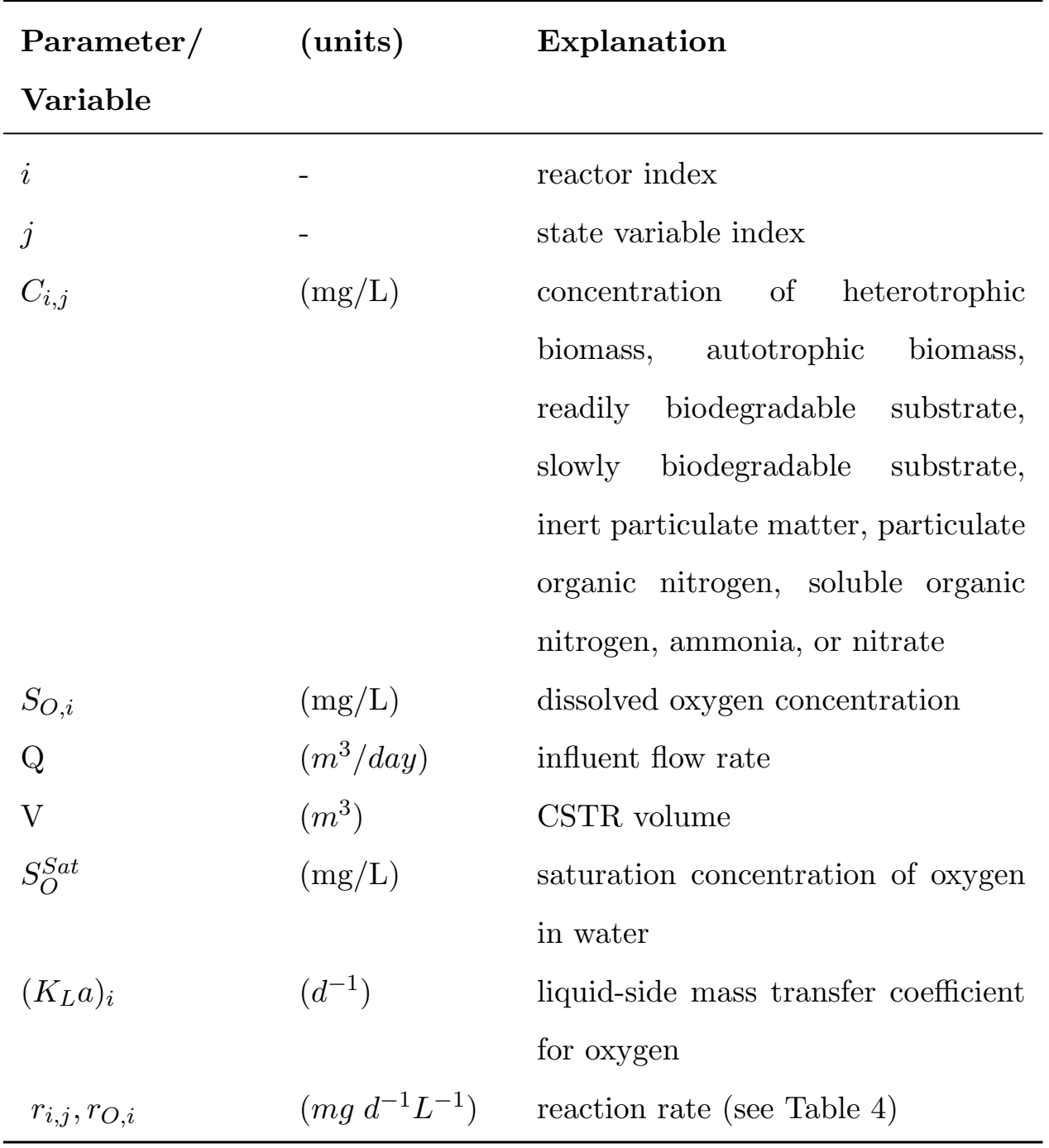

Also, the model assumes ideal operation of the clarifier tank within the designed flow range of the plant. As shown in Figure 1, this leads to equal distribution of soluble components between 


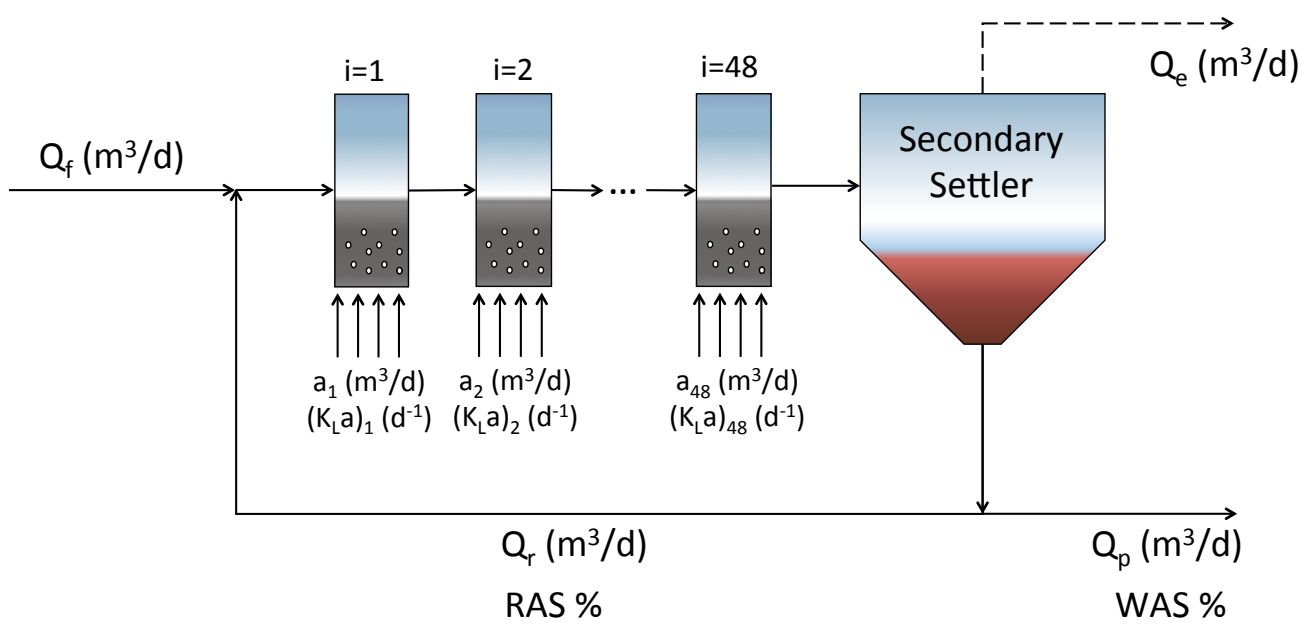

Figure 1: Schematic of the discretized activated sludge process. Solid lines indicate streams where solid and soluble components are mixed, whereas dashed lines show streams that contain negligible amount of solids.

the top and bottom effluent streams of the clarifier, while all solid components are collected at the bottom stream. The clarifier module of the model remains ideal until very high influent flow rates (greater than the maximum capacity) are reached. However, such high flow rates are not used in this study and further details on the clarifier model can be found elsewhere [6].

Table 4: Rate expressions for Activated Sludge Model No. 1.

\section{Species}

Heterotrophic

Biomass

Autotrophic

Biomass

\section{Symbol Rate expression}

$$
X_{B H} \quad \hat{\mu}_{H} \frac{S_{S}}{K_{S}+S_{S}} \frac{S_{O}}{K_{O, H}+S_{O}} X_{B H}
$$

$$
\begin{aligned}
& +\eta_{g} \hat{\mu}_{H} \frac{S_{S}}{K_{S}+S_{S}} \frac{K_{O, H}}{K_{O, H}+S_{O}} \frac{S_{N O}}{K_{N O}+S_{N O}} X_{B H} \\
& -b_{H} X_{B H}
\end{aligned}
$$

$X_{B A}$

$\hat{\mu}_{A} \frac{S_{N H}}{K_{N H}+S_{N H}} \frac{S_{O}}{K_{O, A}+S_{O}} X_{B A}-b_{A} X_{B A}$ 
Slowly

$X_{S} \quad k_{h} \frac{\frac{X_{S}}{X_{B H}}}{K_{X}+\frac{X_{S}}{X_{B H}}}\left\{\frac{S_{O}}{K_{O, H}+S_{O}}\right.$

Substrate

$$
\begin{aligned}
& \left.+\eta_{g} \frac{K_{O, H}}{K_{O, H}+S_{O}} \frac{S_{N O}}{K_{N O}+S_{N O}}\right\} X_{B H} \\
& +\left(1-f_{p}\right)\left(b_{H} X_{B H}+b_{A} X_{B A}\right) X_{B H}
\end{aligned}
$$

Readily

$S_{S}$

$-\frac{\hat{\mu}_{H}}{Y_{H}} \frac{S_{S}}{K_{S}+S_{S}}\left\{\frac{S_{O}}{K_{O, H}+S_{O}}\right.$

Biodegradable

$\left.\eta_{g} \frac{K_{O, H}}{K_{O, H}+S_{O}} \frac{S_{N O}}{K_{N O}+S_{N O}}\right\} X_{B H}$

$+k_{h} \frac{\frac{X_{S}}{X_{B H}}}{K_{X}+\frac{X_{S}}{X_{B H}}}\left\{\frac{S_{O}}{K_{O, H}+S_{O}}\right.$

$\left.\eta_{g} \frac{K_{O, H}}{K_{O, H}+S_{O}} \frac{S_{N O}}{K_{N O}+S_{N O}}\right\} X_{B H}$

Inert Particulate $X_{P} \quad f_{p}\left(b_{H} X_{B H}+b_{A} X_{B A}\right)$

Products

Particulate Or- $X_{N D} \quad\left(i_{X B}-f_{P B} i_{X P}\right)\left(b_{H} X_{B H}+b_{A} X_{B A}\right)$

ganic Nitrogen

$$
\begin{gathered}
-k_{h} \frac{\frac{X_{N D}}{X_{B H}}}{K_{X}+\frac{X_{S}}{X_{B H}}}\left\{\frac{S_{O}}{K_{O, H}+S_{O}}\right. \\
\left.\eta_{g} \frac{K_{O, H}}{K_{O, H}+S_{O}} \frac{S_{N O}}{K_{N O}+S_{N O}}\right\} X_{B H}
\end{gathered}
$$




$$
\begin{aligned}
& \begin{array}{lll}
\text { Soluble Organic } S_{N D} & k_{h} \frac{\frac{X_{N D}}{X_{B H}}}{K_{X}+\frac{X_{S}}{X_{B H}}}\left\{\frac{S_{O}}{K_{O, H}+S_{O}}\right.
\end{array}+ \\
& \left.\eta_{g} \frac{K_{O, H}}{K_{O, H}+S_{O}} \frac{S_{N O}}{K_{N O}+S_{N O}}\right\} X_{B H} \\
& \text { Ammonia } \\
& S_{N H} \\
& -i_{X B} \hat{\mu}_{H} \frac{S_{S}}{K_{S}+S_{S}}\left\{\frac{S_{O}}{K_{O, H}+S_{O}}\right. \\
& \left.\eta_{g} \frac{K_{O, H}}{K_{O, H}+S_{O}} \frac{S_{N O}}{K_{N O}+S_{N O}}\right\} X_{B H} \\
& -\hat{\mu}_{A}\left(i_{X B}+\frac{1}{Y_{A}}\right) \frac{S_{N H}}{K_{N H}+S_{N H}} \frac{S_{O}}{K_{O, A}+S_{O}} X_{B A}+ \\
& k_{a} S_{N D} X_{B H} \\
& \text { Nitrate } \quad S_{N O} \quad-\hat{\mu}_{H} \eta_{g} \frac{1-Y_{H}}{2.86 Y_{H}} \frac{S_{S}}{K_{S}+S_{S}} \frac{K_{O, H}}{K_{O, H}+S_{O}} \frac{S_{N O}}{K_{N O}+S_{N O}} X_{B H} \\
& +\frac{\hat{\mu}_{A}}{Y_{A}} \frac{S_{N H}}{K_{N H}+S_{N H}} \frac{S_{O}}{K_{O, A}+S_{O}} X_{B A} \\
& \text { Oxygen } \\
& S_{O} \quad-\hat{\mu}_{H} \frac{1-Y_{H}}{Y_{H}} \frac{S_{S}}{K_{S}+S_{S}} \frac{S_{O}}{K_{O, H}+S_{O}} X_{B H} \\
& -\hat{\mu}_{A} \frac{4.57-Y_{A}}{Y_{A}} \frac{S_{N H}}{K_{N H}+S_{N H}} \frac{S_{O}}{K_{O, A}+S_{O}} X_{B A}
\end{aligned}
$$

\section{Uniformly Distributed Aeration}

Like many WRPs, Stickney WRP normally uses equal airflow rates in each zone of the aeration tank. In the rest of the present study, this mode of operation will be referred to as "uniformly distributed aeration (UDA)". It is important to demonstrate the changes that occur in the reactor as the total amount of air is reduced using UDA profiles. For this purpose, we will only consider the steady state response for each scenario, leaving the discussion of dynamic scenarios to subsequent sections. In each case, three state variables are monitored for compliance with the effluent permit regulations. These are ammonia and oxygen concentrations in the effluent, in addition to the first location in the tank where the ammonia concentration drops below $0.10 \mathrm{mg} / \mathrm{L}$. While the latter is not an explicit state variable in the model, it can be considered as a measure of robustness of the 
process. As it will be evident in further sections, beyond meeting the effluent permits, it is also critical to keep the ammonia concentration as low as possible near the outlet of the tank. This ensures that the untreated ammonia is not discharged from the tank in the case of events that reduce the residence time of the tank, such as storms.

\subsection{Nominal configuration}

Based on the average conditions obtained from the historical plant data (Table 2.1), air at a rate of $17.56 \mathrm{MCFD}\left(497,328 \mathrm{~m}^{3} /\right.$ day or $10,361 \mathrm{~m}^{3} /$ day per CSTR) is pumped into the tank in UDA configuration. This configuration, shown in Figure $2 \mathrm{~b}$ along with steady state ammonia and oxygen profiles (Figure 2a), leads to effluent ammonia and oxygen concentrations that satisfy the NPDES discharge permits.

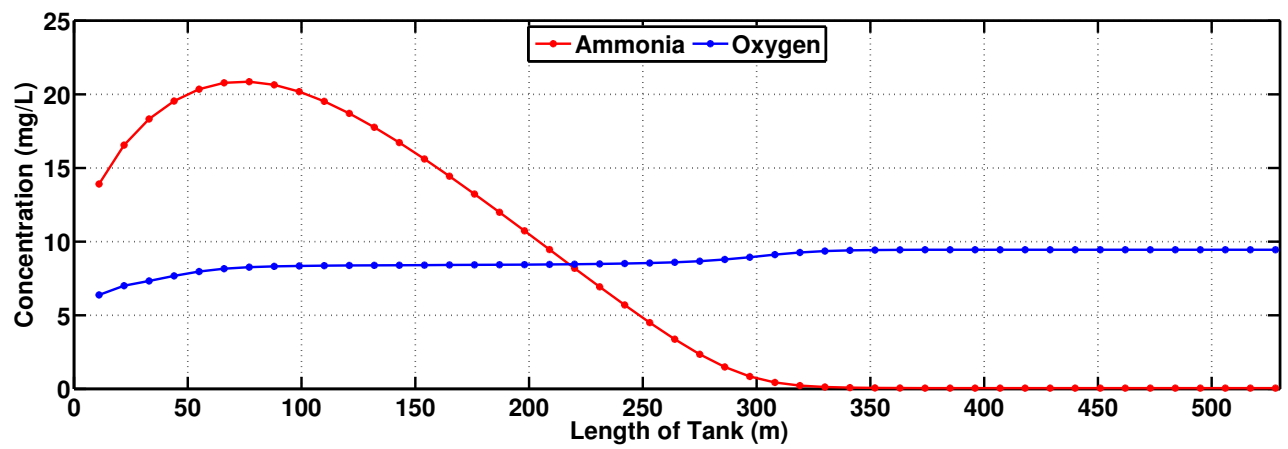

(a)

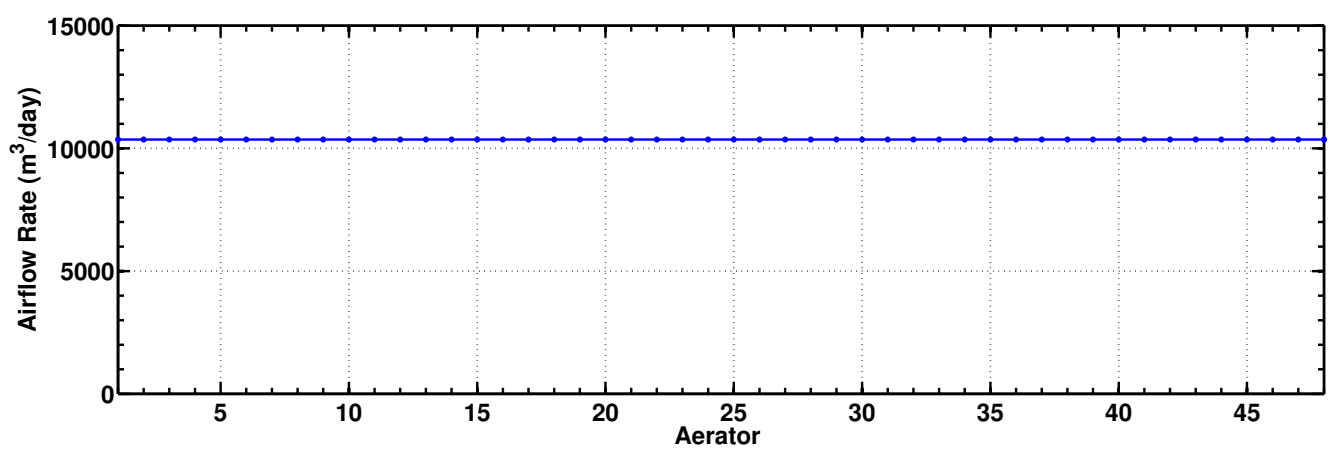

(b)

Figure 2: (a) Dissolved oxygen and ammonia concentration profiles across the activated sludge tank at steady state using the nominal aeration profile, (b) Nominal UDA profile. All other process parameters are as given in Table 2.1.

We also see in Figure 2 that the ammonia concentration falls below the threshold value of 
$0.10 \mathrm{mg} / \mathrm{L}$ (i.e. the default effluent constraint for ammonia) $335 \mathrm{~m}$ into the tank. This further verifies the current flexibility of the process towards disturbances. Despite that flexibility, it can be also seen that starting from $350 \mathrm{~m}$ into the tank, no improvement to the dissolved oxygen or ammonia concentration takes place. This clearly indicates excessive aeration, majorly for the sake of operational safety, and leads to very high energy usage. It is fairly possible to surmount this situation with adequate optimization of the air usage to utilize the tank space uniformly, and with robust control systems to ensure flexibility towards disturbances and operational safety. Next, we investigate the boundary of such optimization when a UDA profile is utilized.

\subsection{Reduction of air usage with UDA profiles}

As an initial approach, it is important to explore how much air can be saved by reducing the total rate of aeration with a UDA configuration, while preserving the nominal effluent quality. For this reason, cases that utilize $30 \%, 60 \%$ and $70 \%$ less aeration rates than the nominal aeration rate were simulated. The steady state concentration profiles of ammonia and dissolved oxygen can be seen in Figure 3a for 30\% less, in Figure 3b for $60 \%$ less, and in Figure 3c for $70 \%$ less aeration rates.

As shown in Figure 3a, values of ammonia and dissolved oxygen concentrations in the effluent are practically the same as the nominal configuration using only $70 \%$ of the nominal aeration rate. In this case, effluent ammonia concentration is $0.05 \mathrm{mg} / \mathrm{L}$, while oxygen concentration is 9.41 $\mathrm{mg} / \mathrm{L}$. Also, we see that the ammonia concentration falls below $0.10 \mathrm{mg} / \mathrm{L}$ by $335 \mathrm{~m}$ into the tank, similar to the nominal case (Figure 2). This shows that the total aeration rate can be reduced by at least $30 \%$ without affecting the effluent quality.

However, if the total aeration rate is $60 \%$ less than the nominal rate of aeration (Figure $3 \mathrm{~b}$ ), effluent ammonia concentration reaches $0.16 \mathrm{mg} / \mathrm{L}$ and the default effluent constraint for ammonia is no longer satisfied, although NPDES effluent permits are still met. In addition, the effluent oxygen concentration is $8.23 \mathrm{mg} / \mathrm{L}$, which is just below the corresponding default effluent constraint. Though the NPDES discharge permits are met, an effluent ammonia concentration of $0.16 \mathrm{mg} / \mathrm{L}$ poses a risk of discharging untreated ammonia from the tank in events such as storms.

When we further reduce the aeration rate by $70 \%$ from its nominal value (Figure 3c), the tank is no longer provided with the amount of oxygen that is essential for the treatment process. At steady state, such conditions lead to a high effluent ammonia concentration and the violation of 

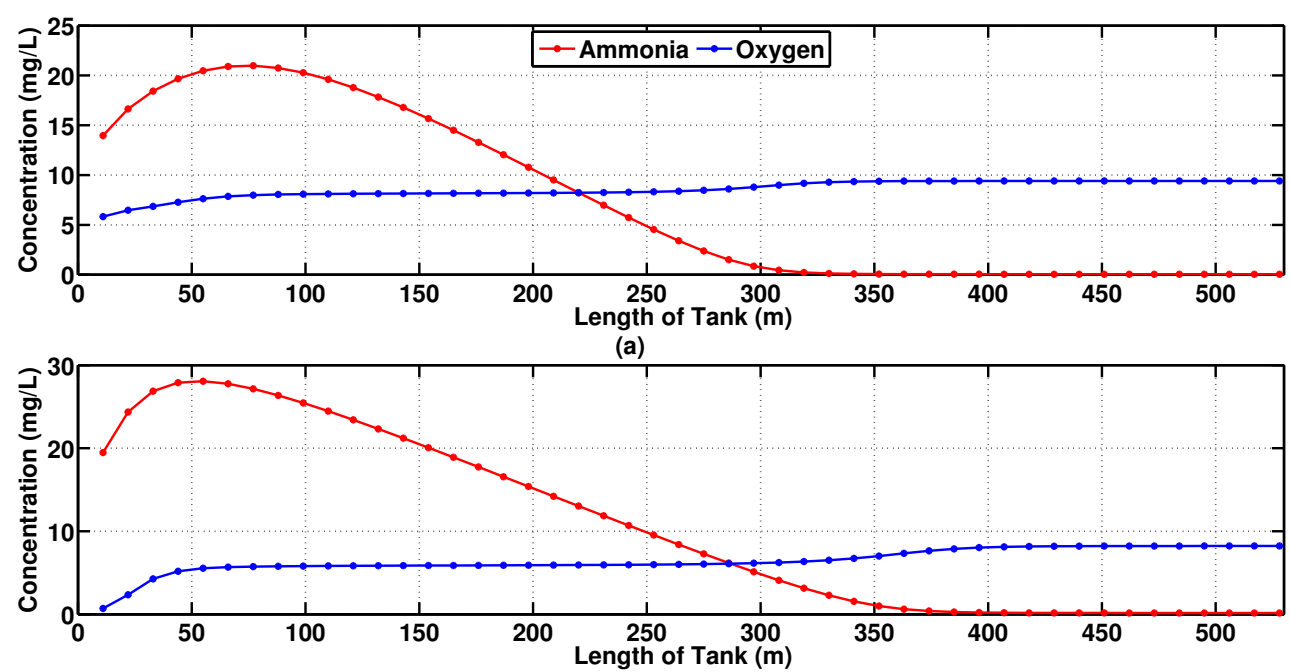

(b)

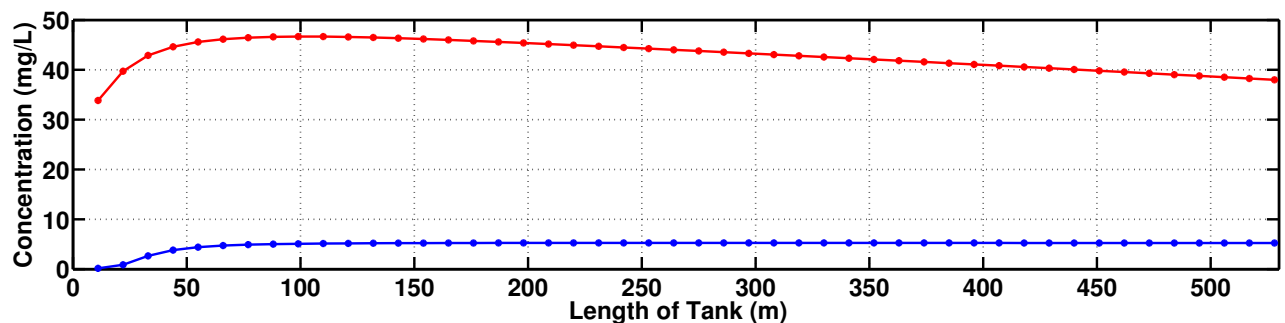

(c)

Figure 3: Steady state ammonia and dissolved oxygen concentration profiles using (a) 30\%, (b) $60 \%$ and (c) $70 \%$ less aeration than the nominal aeration rate in UDA configuration. All other parameters are as given in Table 2.1.

NPDES discharge permits, as seen in Figure 3c. This happens as a result of the increased anoxic metabolism of the heterotrophic biomass, as well as insufficient nitrification by the autotrophic biomass [6]. Thus, it becomes apparent that the process has a certain "critical" (or threshold) rate of aeration under certain process conditions, below which proper treatment is not possible. This critical rate of aeration is important in that it constitutes a natural lower boundary of the activated sludge process for the optimization of air usage and is further discussed in the next section.

\subsection{The critical profile}

To conclude the analysis of the UDA configurations, it is important to identify the critical airflow rate needed to maintain the effluent quality within the default effluent constraints. Figure 4 shows the ammonia and dissolved oxygen concentration profiles when the critical rate of aeration is used with a UDA configuration. The critical profile corresponds to an aeration rate that is $59.5 \%$ 

to detect in the real process.

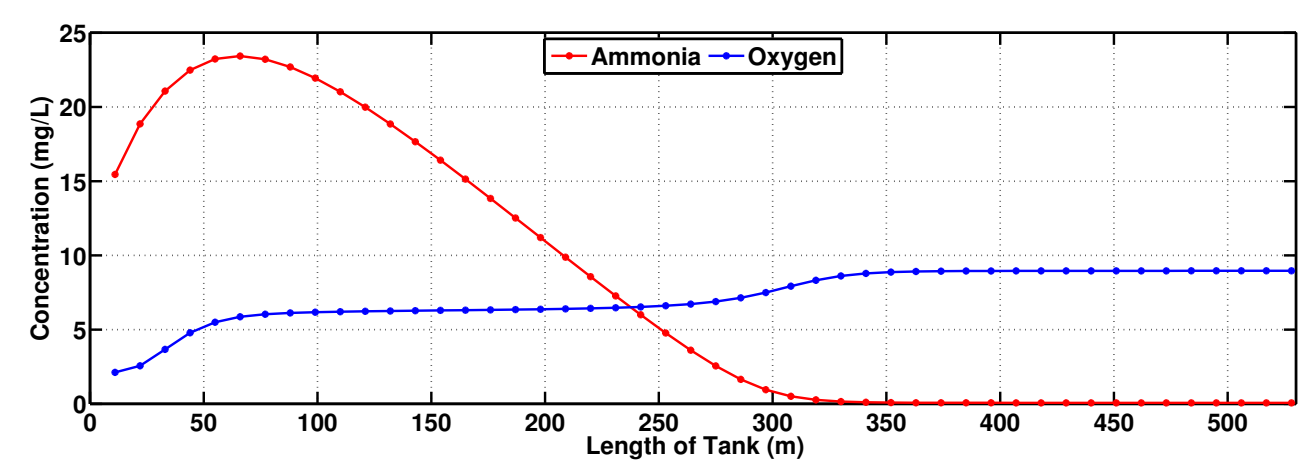

Figure 4: Steady state concentrations of ammonia and dissolved oxygen using the critical rate of aeration.

less than the nominal air usage, which results in an effluent ammonia concentration of $0.07 \mathrm{mg} / \mathrm{L}$ and an effluent oxygen concentration of $8.96 \mathrm{mg} / \mathrm{L}$ at steady state. Also, ammonia concentration drops below $0.10 \mathrm{mg} / \mathrm{L}$ after $340 \mathrm{~m}$ into the tank. It should be noted that practically these effluent concentrations are equivalent to those in the nominal case, since the difference would be very hard

While the critical rate of aeration can maintain the effluent quality within the default effluent constraints defined in Section 2.1, it may not be able to do so under transient events, such as storms, or changes in the influent composition and amount. Table 3.3 summarizes different UDA profiles utilized and the corresponding effluent quality, location in the tank where ammonia concentration falls below $0.10 \mathrm{mg} / \mathrm{L}$, and savings in aeration compared to the nominal case. Despite the small difference between the aeration rates of the $60 \%$ less and the critical aeration $(59.5 \%$ less $)$ cases, we see that the ammonia concentration in the effluent is halved in response to an increase of $0.5 \%$ of the nominal aeration rate. This, along with our previous work [6], demonstrates the high sensitivity of the process toward aeration.

As wastewater undergoes treatment and travels through the tank, its composition also changes. Therefore the oxygen demand and the required local airflow rate vary throughout the tank. UDA profiles cannot accommodate this spatial variation in the aeration requirement, and consequently, are not useful for the minimization of the total aeration rate. On the other hand, a nonuniform aeration (NUA) profile can target the aeration requirements of individual zones better to maximize the savings in aeration. Use of NUA profiles requires the calculation of local aeration rates throughout the tank, and this is ideally done through optimization, which is discussed in the next 
section.

\section{Optimization of Aeration Profile at Steady State}

In order to implement the more optimal NUA profiles, one needs to calculate zone-specific aeration requirements. This can be cast as a nonlinear constrained optimization problem, such as given in Eq. (4).

$$
\begin{aligned}
\min _{a_{1}, \ldots, a_{48} \in \mathbb{R}^{+}} & \sum_{i=1}^{48} a_{i} \\
\text { subject to } & \frac{d C_{i, j}}{d t}=\frac{d S_{O, i}}{d t}=0 \\
& 1500 \leq a_{i} \leq 15,000 \mathrm{~m}^{3} / d a y \\
& S_{N H, 48} \leq 0.1 \mathrm{mg} / \mathrm{L} \\
& S_{O, 48} \geq 8.5 \mathrm{mg} / \mathrm{L}
\end{aligned}
$$

According to Eq. (4), the optimization problem requires the solution of the steady state model equations given in Eqs. (1) and (2) with the default effluent constraints (Eqs. (4d) and (4e)) as defined in Section 2.1. Also, a lower and upper bound on local airflow rates $\left(a_{i}\right)$ are imposed on the problem, which represent the minimum airflow rate necessary for mixing and the maximum airflow rate allowed, respectively. An important point to note here is the computational burden associated with the optimization, which involves the choice of 48 variables and the solution of 480

Table 5: Summary of results for UDA profiles at different aeration rates.

\begin{tabular}{lllll}
\hline Case & $\begin{array}{l}\text { Airflow } \\
(\mathbf{M C F D})\end{array}$ & $\begin{array}{l}\text { Oxygen } \\
(\mathbf{m g} / \mathbf{L})\end{array}$ & $\begin{array}{l}\text { Ammonia } \\
(\mathbf{m g} / \mathbf{L})\end{array}$ & $\begin{array}{l}\text { Distance } \\
(\mathbf{m})\end{array}$ \\
\hline Nominal (100\%) & 17.56 & 9.45 & 0.05 & 335 \\
$30 \%$ less & 12.29 & 9.41 & 0.05 & 335 \\
$60 \%$ less & 7.025 & 8.23 & 0.16 & - \\
$70 \%$ less & 5.269 & 5.23 & 37.9 & - \\
Critical (59.5\%) & 6.860 & 8.96 & 0.07 & 340 \\
\hline
\end{tabular}


highly nonlinear algebraic equations. Due to the problem size and the various local minima that can be achieved using 48 airflow rates, a nonlinear constrained optimization approach was not able to solve this problem. In order to implement the optimized aeration profiles in the activated sludge tank, or update the aeration profile as influent conditions change, the optimization procedure needs to complete in a reasonable time. Since this was not possible with the problem in Eq. (4) using constrained nonlinear optimization, the problem needs to be simplified to allow optimization within a reasonable time, while providing a similar minimization as the original optimization problem.

In our study, this simplification was realized by allowing a certain number of zones (or CSTRs/ aerators) to be pivots in the activated sludge tank. Such a configuration can be seen in Figure 5 with an arbitrary aeration profile. The airflow rates and locations of these pivots (shown as asterisks) are chosen by the optimization routine, while the aeration rates in other zones are calculated via linear interpolation. This requires the modification of Eq. (4) to the following form given in Eq. (5), using 4 pivot CSTRs with locations $1, j, k$, and 48. The number of interior pivots was determined to be $2(j$ and $k$ ) so as to represent each of the two plateaus observed in the dissolved oxygen profiles (see Figures $3 \mathrm{a}-\mathrm{c}$ and 4 ). This way, an approximation of the ideal aeration profile (i.e. the solution of the problem in Eq. (4)) can be obtained. In that regard, optimality refers to the solution of Eq. (5) in the rest of this paper and should not be confused with the absolute optimum, which would be obtained by solving Eq. (4).

$$
\begin{array}{ll}
\min _{\substack{a_{1}, a_{j}, a_{k}, a_{48} \in \mathbb{R}^{+} \\
j, k \in \mathbb{Z}^{+}}} & \sum_{i=1}^{48} a_{i} \\
\text { subject to } & \frac{d C_{i, j}}{d t}=\frac{d S_{O, i}}{d t}=0 \\
& 1500 \leq a_{i} \leq 15,000 \mathrm{~m}^{3} / d a y \\
& S_{N H, 48} \leq 0.1 \mathrm{mg} / \mathrm{L} \\
& S_{O, 48} \geq 8.5 \mathrm{mg} / \mathrm{L} \\
& 2 \leq j \leq 24 \\
& 25 \leq k \leq 47
\end{array}
$$

An important implication of Eq. (5) is the introduction of integers to the optimization problem. Since the pivot CSTR locations have to be integers between 1 and 48, the optimization problem 
transforms into a mixed-integer nonlinear programming (MINLP) problem. Also, because the remaining 44 airflow rates are calculated using the airflow rates of the neighboring pivots, two pivots are fixed to first and last zones of the tank. However, the airflow rates of these fixedlocation pivots are still optimization variables. In the absence of such a configuration (i.e. none of the pivots are fixed to a location, regardless of the number), it would be necessary to fix the airflow rates in the first and last zones of the tank to allow the interpolation of airflow rates. In our study, this was avoided, since fixing any airflow rate would effectively limit the extent of the minimization.

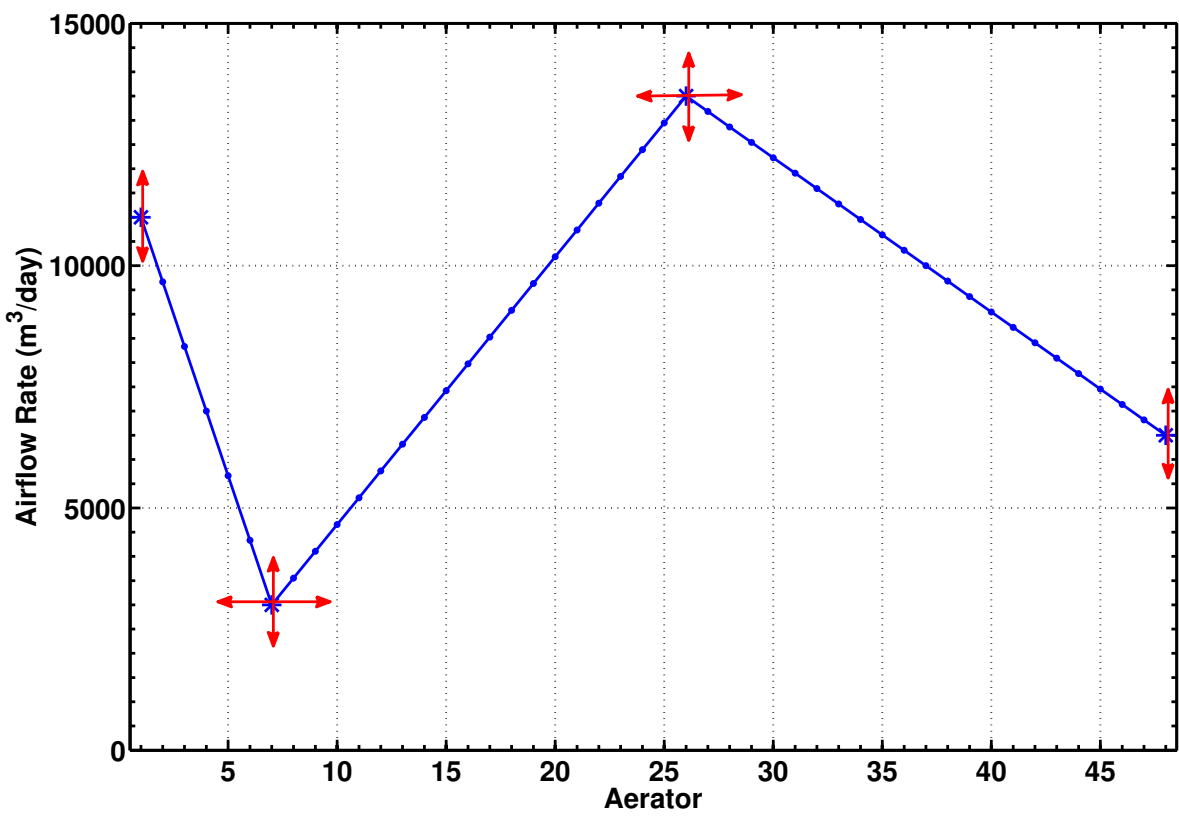

Figure 5: Representation of the optimization problem given in Eq. (5). An arbitrary aeration profile is shown, where stars denote pivot locations and arrows show the ability of change in the corresponding direction. Aeration values for other zones, shown as dots, were interpolated using the neighboring pivot values.

Furthermore, we confine each interior pivot to a certain part of the tank for computational efficiency. In Eqs. (5f) and (5g), pivot $j$ is assigned to the first half of the activated sludge tank, whereas $k$ is allowed in the other half. This prevents redundant aeration profile configurations through the switching of locations by these pivots during optimization.

Contrary to the 48-variable nonlinear optimization problem in Eq. (4), the 6-variable MINLP problem in Eq. (5) can be solved with methods such as genetic algorithms (GA) or ant colony 
optimization. In this study, we use the GA toolbox of MATLAB, which finds a local minimum of the problem [18]. As a result of the smaller number of optimization variables and the ability of GA to escape local minima, the obtained local minimum is expected to be fairly close to the global minimum of the problem. The genetic algorithm creates a certain number of candidate solutions, called the initial population, and evaluates these for fitness to the defined conditions. The solutions with best fitness (elites) are passed on to the next iteration (generation), in addition to new solutions (children) that are created through fit solutions (parents). Then, one of these parents can be modified (mutation) or both parents can be used to generate a solution (crossover), which will be passed on to the next generation. Through the iteration of generations, GA eventually converges on a local minimum of the problem. Further details about genetic algorithms and the toolbox utilized can be found elsewhere $[18,19]$.

\subsection{Optimization results}

The aeration profile obtained upon solving the MINLP problem given in Eq. (5) with 4 pivot CSTRs and the conditions in Table 2.1 is shown in Figure 6. Here, we see that the optimization routine urges the aerators in the first and last CSTRs to relatively higher aeration rates, while allowing the inner ones to utilize much lower values. This results in a total aeration rate of 140,585 $\mathrm{m}^{3} /$ day, which is almost $72 \%$ less than the nominal aeration rate of 497,328 $\mathrm{m}^{3} /$ day. In Figure 6 , we see that the optimized aeration profile achieves fairly similar effluent concentrations as the nominal operation. Upon using the aeration profile in Figure 6b, an effluent dissolved oxygen concentration of $8.51 \mathrm{mg} / \mathrm{L}$, and an effluent ammonia concentration of $0.08 \mathrm{mg} / \mathrm{L}$ is achieved. This shows that, through utilization of suitable aeration profiles, lower aeration rates do not necessarily compromise the effluent quality, and indeed allow nearly the same effluent quality as high-aeration operation. This is further supported by the concentration profiles shown in Figure 6a. The concentration profile of ammonia indicates that the concentration drops below $0.10 \mathrm{mg} / \mathrm{L}$ about $360 \mathrm{~m}$ into the activated sludge tank, which is fairly close to $335 \mathrm{~m}$ obtained under nominal aeration. Similarly, the dissolved oxygen concentration reaches above $5 \mathrm{mg} / \mathrm{L}$ about the same point in the tank, and is only boosted above $8 \mathrm{mg} / \mathrm{L}$ toward the exit of the tank. Note that, by this point in the tank, the aeration serves mainly to increase the dissolved oxygen in the activated sludge rather than the biochemical treatment. Therefore the increase in aeration rates just prior to the outlet of the tank does not impose any major risk on the treatment. 


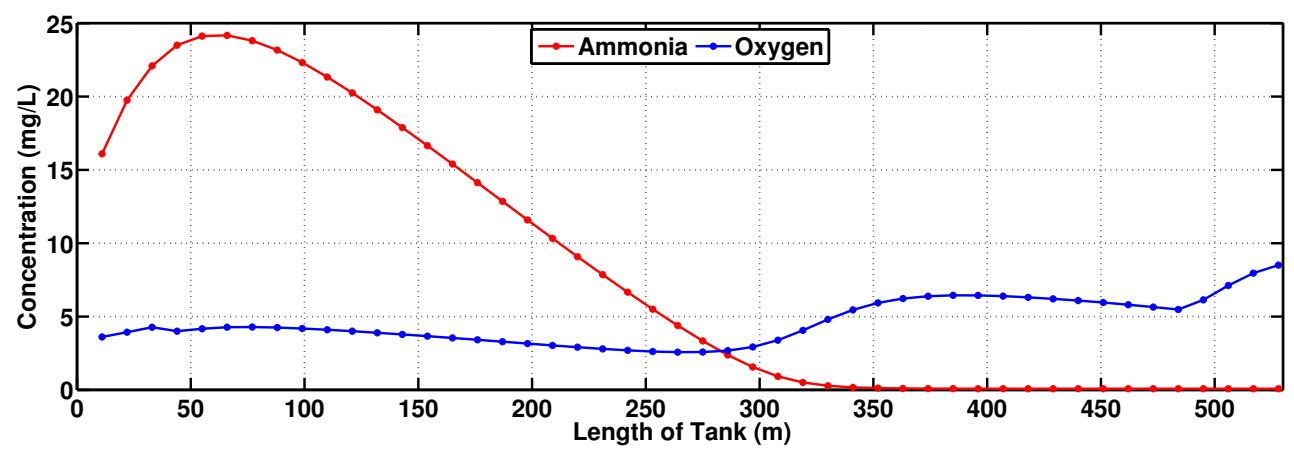

(a)

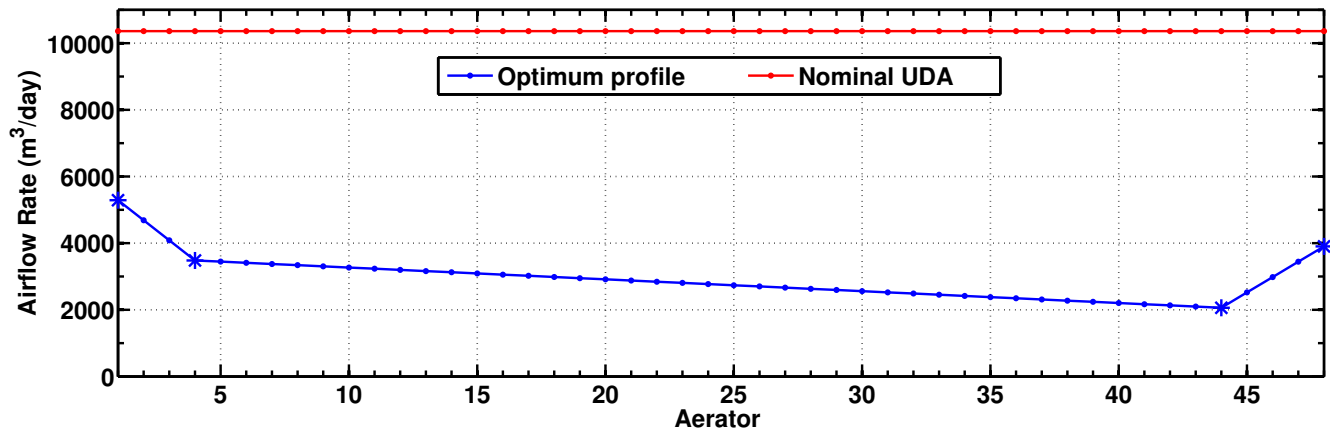

(b)

Figure 6: (a) Concentration profiles of ammonia and dissolved oxygen, (b) aeration profile resulting from a 4-pivot solution of Eq. (5) under the conditions given in Table 2.1. Nominal aeration is also shown as the red/gray line. Stars show pivot CSTRs, whereas dots show the aeration values calculated through linear regression.

Overall, the profile is a decreasing one, as one would expect considering the decreasing oxygen demand toward the outlet of the tank. Usually, the inlet portion of the activated sludge tank, where the raw wastewater influent and the return activated sludge (RAS) from the clarifier meet, has a much higher oxygen demand compared to the rest of the tank. As organic matter is transported through the tank, it is more readily broken down into simpler molecules by the biomass, and therefore oxygen demand toward the outlet of the tank decreases considerably. This phenomenon can be greatly exploited to save on aeration, if quantified adequately as shown in Figure 6 .

It is also possible to see the significance of having pivot CSTRs across the tank in Figure 6. In the absence of the interior pivots, the aeration profile shown in Figure 6 would be a sloped line connecting the first and last pivots. While this would allow a lower aeration rate than the nominal case, this profile would still be less optimal than its counterpart in Figure 6, as the interior sections 
of the tank would be over-aerated. Indeed, such a profile would require a total aeration rate of $228,000 \mathrm{~m}^{3} /$ day, $62 \%$ more than the total aeration rate in Figure 6 .

The optimal aeration profile provides sufficient aeration to the process in the absence of substantial transient events. However, external disturbances, such as prolonged storms, may render this profile inefficient and affect the effluent quality if a robust control system is not present. Still, the optimal aeration profile can be fortified with a safety factor to help the process endure severe disturbances. In the present case, a 30\% increase in all local airflow rates proves to be sufficient against major storm events, and will be discussed further in Section 5. In the absence of automatic control, such a safety factor allows the plant to use the same aeration profile for varying operating conditions. Ideally, however, the offline optimization would be carried out regularly to update the aeration profile as necessary. Concentration profiles of ammonia and dissolved oxygen obtained upon using this fortified aeration profile (briefly referred to as $1.3 \times$ Optimum) can be seen in Figure 7.

As seen in Figure 7 , the main effect of $1.3 \times$ Optimum profile is the enhancement of the dissolved oxygen concentration across the tank (over $5 \mathrm{mg} / \mathrm{L}$ in all locations) and a smoother increase toward the tank outlet (compared to Figure 6). It should also be noted that the peak in the ammonia profile decreases from $25 \mathrm{mg} / \mathrm{L}$ in Figure 6 to about $21 \mathrm{mg} / \mathrm{L}$ in Figure 7. Also, with a $30 \%$ increase in local aeration rates (which corresponds to $63.3 \%$ less aeration than the nominal profile), the ammonia concentration falls below $0.10 \mathrm{mg} / \mathrm{L}$ past $340 \mathrm{~m}$ into the tank.

A comparison of the Nominal, Critical, Optimum and $1.3 \times$ Optimum aeration profiles can be found in Table 4.1. The 30\% increase in aeration over the Optimum profile accounts for only an $8.4 \%$ sacrifice of savings, as shown in Table 4.1. However, as we show in Section 5, this sacrifice serves to protect the process against excessive and prolonged storm events. Also, it is notable that this $30 \%$ increase in aeration allows the process to have nearly identical performance as the nominal aeration profile in terms of effluent ammonia and dissolved oxygen concentrations, while still offering $63 \%$ savings in aeration.

\subsection{Effect of temperature}

An important factor determining the overall rate of aeration needed for the activated sludge process is the wastewater temperature. Earlier, we have demonstrated the necessity of higher rates of aeration at high water temperatures through a two-parameter continuation study [6]. Despite 


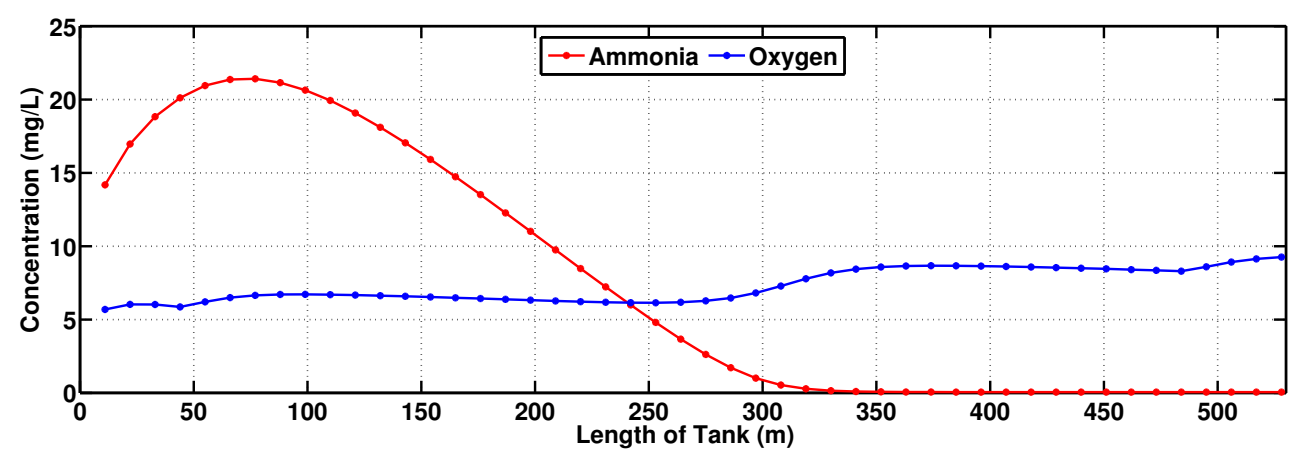

(a)

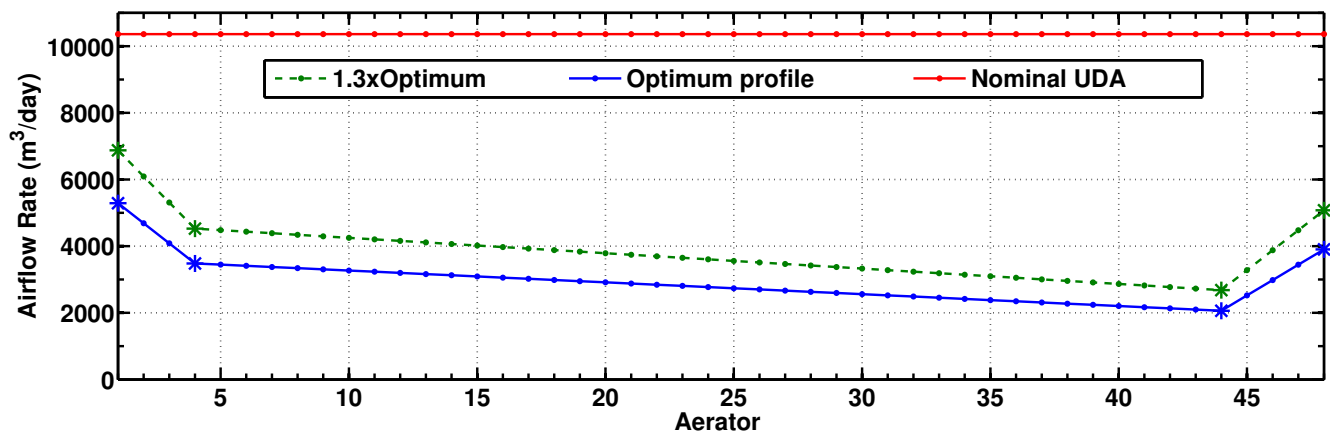

(b)

Figure 7: (a) Concentration profiles for ammonia and dissolved oxygen when the local airflow rates in the Optimum aeration profile are increased by $30 \%$ (1.3xOptimum) (b) 1.3xOptimum (dashed line), Optimum (blue/black line) and Nominal (red/gray line) aeration profiles. All other process parameters are as given in Table 2.1. Stars show pivot CSTRs, whereas dots show the aeration rates calculated through linear regression.

Table 6: Summary of results for different profiles. Critical profile, which is a UDA profile, is provided here for comparison.

\begin{tabular}{|c|c|c|c|c|c|}
\hline Case & $\begin{array}{l}\text { Airflow } \\
\text { (MCFD) }\end{array}$ & $\begin{array}{l}\text { Oxygen } \\
(\mathrm{mg} / \mathrm{L})\end{array}$ & $\begin{array}{l}\text { Ammonia } \\
(\mathrm{mg} / \mathrm{L})\end{array}$ & $\begin{array}{l}\text { Distance } \\
(\mathrm{m})\end{array}$ & $\begin{array}{l}\text { Savings } \\
(\%)\end{array}$ \\
\hline Nominal & 17.56 & 9.48 & 0.05 & 335 & 0.00 \\
\hline Critical & 7.113 & 8.96 & 0.07 & 340 & 59.5 \\
\hline Optimum & 4.970 & 8.51 & 0.08 & 360 & 71.7 \\
\hline $1.3 \times$ Optimum & 6.446 & 9.25 & 0.05 & 340 & 63.3 \\
\hline
\end{tabular}


the higher reaction rates at high water temperatures, the solubility of oxygen in water is greatly hindered. Naturally, this requires higher rates of aeration to achieve the same dissolved oxygen concentration as a mild temperature day. Here, we show that high-temperature operation not only requires a higher rate of aeration, but also a different distribution of aeration rates across the tank.

According to the historical plant data from Stickney WRP, the highest daily-average wastewater temperature recorded was $30{ }^{\circ} \mathrm{C}$. In order to test the $1.3 x$ Optimum aeration profile (which was calculated for a wastewater temperature of $17.4{ }^{\circ} \mathrm{C}$ ), a steady state simulation with the same conditions and aeration profile as in Figure 7 was carried out, except for a water temperature of $30{ }^{\circ} \mathrm{C}$. The resulting concentration profiles of ammonia and dissolved oxygen are given in Figure 8.
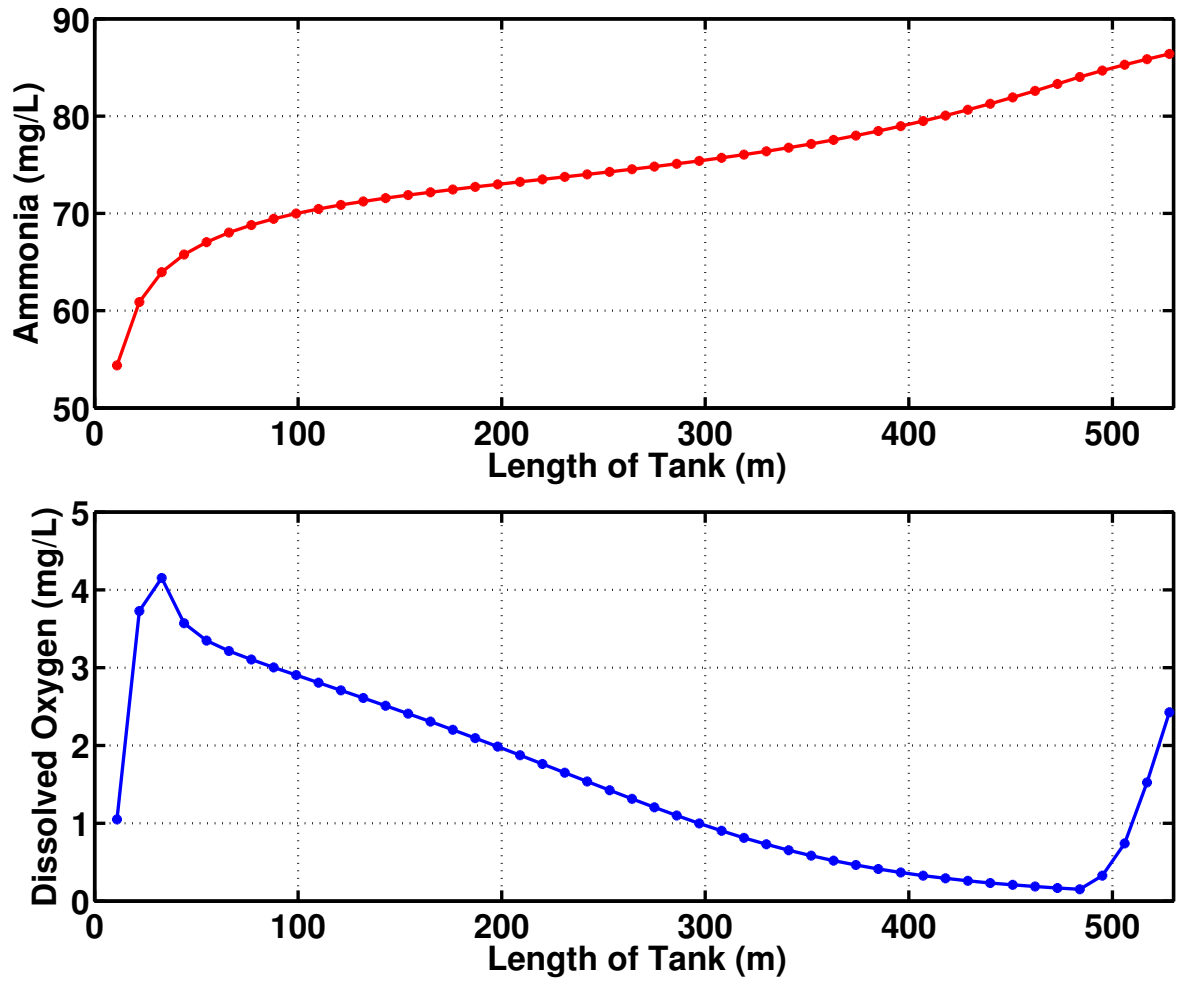

Figure 8: Concentration profiles of ammonia and dissolved oxygen when the $1.3 \times$ Optimum aeration profile (Figure $7 \mathrm{~b}$ ) is used with a wastewater temperature of $30^{\circ} \mathrm{C}$. All other process parameters are as given in Table 2.1.

As depicted in Figure 8, the optimized aeration profile is not suitable for operation at high water temperatures. At steady state, the ammonia concentration across the tank is above $50 \mathrm{mg} / \mathrm{L}$ and severely violates the NPDES permits. The same can be said for dissolved oxygen, which remains 
below $4 \mathrm{mg} / \mathrm{L}$ in all locations and increases slightly only toward the outlet of the tank.

The aeration profile calculated for a water temperature of $17.4{ }^{\circ} \mathrm{C}$ is not robust at $30{ }^{\circ} \mathrm{C}$, and therefore requires another optimization specific to such conditions. Indeed, when the optimization is carried out at $30^{\circ} \mathrm{C}$, we see that the resulting aeration profile, given in Figure $9 \mathrm{~b}$, is very different from its counterpart in Figure 7b. The aeration profile shown in Figure 9b employs a much wider decreasing profile in the first portion of the tank with 16 CSTRs, compared to the 4 CSTRs in Figure 7. This is in clear agreement with the increased aeration requirement as a result of lower solubility of oxygen at high water temperatures, specifically around the inlet region of the tank. As a result of this new aeration profile, a total aeration rate of $216,750 \mathrm{~m}^{3} / \mathrm{d}(56.4 \%$ less than the nominal aeration rate) is utilized to give effluent concentrations of $0.05 \mathrm{mg} / \mathrm{L}$ of ammonia and 7.06 $\mathrm{mg} / \mathrm{L}$ of dissolved oxygen, as shown in Figure 9a. In addition, as a result of the elevated water temperature and sufficient aeration, the point in the tank where ammonia concentration drops below $0.10 \mathrm{mg} / \mathrm{L}$ moves to $180 \mathrm{~m}$ into the tank, which can be attributed to the faster kinetics of nitrification at elevated water temperatures.

It is important to note that, in order to carry out the optimization at temperatures as high as $30{ }^{\circ} \mathrm{C}$, one needs to update the default effluent constraint on dissolved oxygen. This is necessary, since the original optimization problem given in Eq. (5) requires an effluent dissolved oxygen concentration of at least $8.5 \mathrm{mg} / \mathrm{L}$, which cannot be reached at $30{ }^{\circ} \mathrm{C}$. In Figure 9, the optimization was carried out with a modification of the default effluent constraint on dissolved oxygen (Eq. (5e)), which requires the concentration to be greater than $6.5 \mathrm{mg} / \mathrm{L}(85.5 \%$ of the saturation concentration at $30{ }^{\circ} \mathrm{C}$ ). As seen in Figure 9a, this constraint is sufficient to bring the effluent dissolved oxygen concentration to $7.06 \mathrm{mg} / \mathrm{L}$, fairly close to the saturation value of $7.60 \mathrm{mg} / \mathrm{L}$.

\section{Dynamic Response Analysis}

So far, we have only analyzed the steady state response of the activated sludge process using a number of different aeration profiles. On the other hand, transient events are frequently encountered in WRPs and may pose a threat to safe operation depending on their duration and magnitude. Therefore, it is important to investigate the dynamic behavior of the process under transient events, in order to better understand the robustness of the optimal aeration profiles presented in the previous sections. Since storm events usually constitute the major concern for WRPs, 


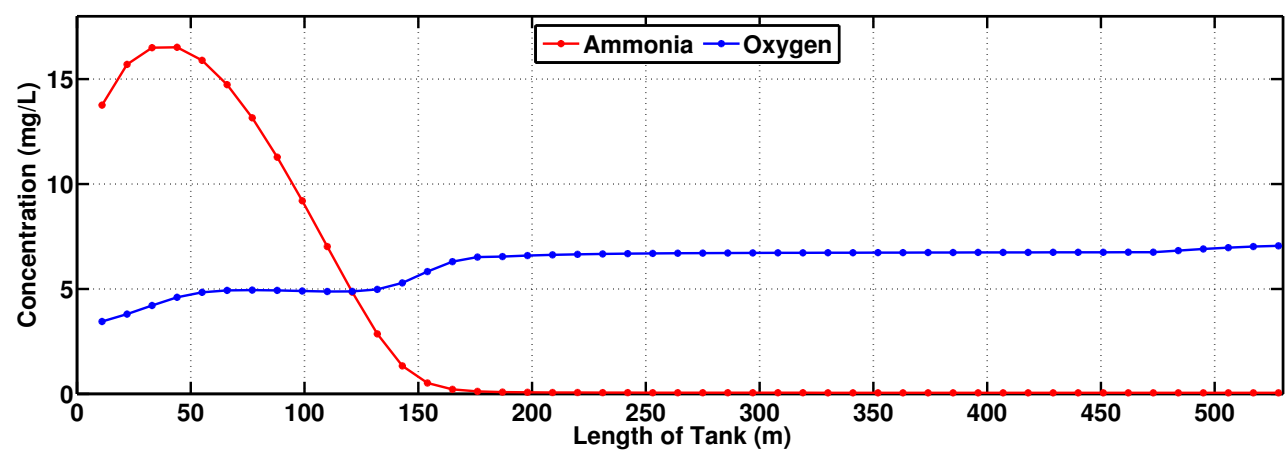

(a)

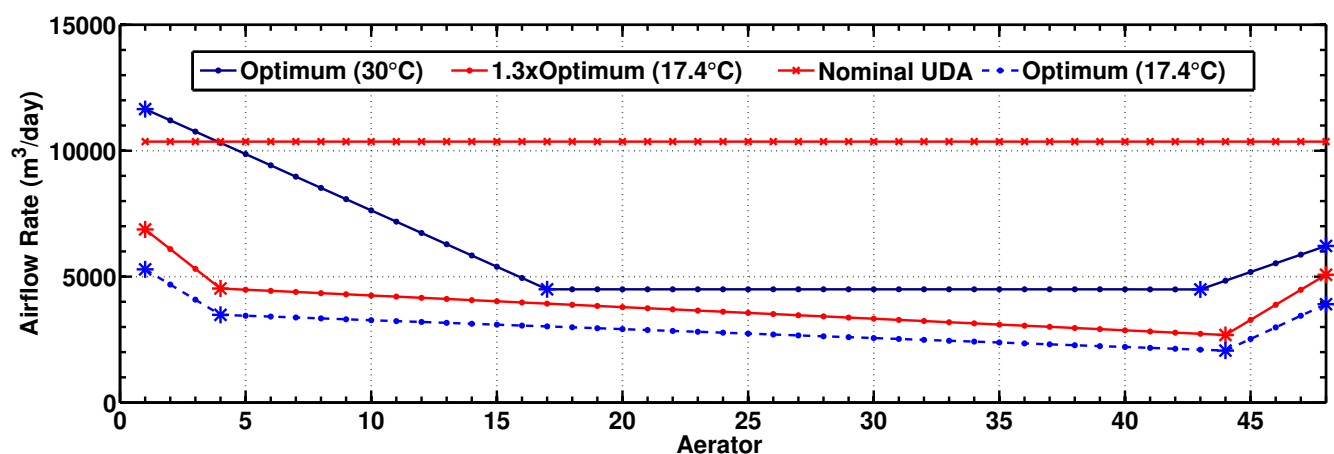

(b)

Figure 9: (a) Concentration profiles of ammonia and dissolved oxygen when the Optimum aeration profile, recalculated for operation at a water temperature of $30{ }^{\circ} \mathrm{C}$, is used. (b) Optimum aeration profile recalculated at 30 ${ }^{\circ} \mathrm{C}$, along with previously calculated aeration profiles.

we focus on a 2-day storm event in this study, which increases the flow rate in the tank close to the design maximum. The storm duration and magnitude were chosen as a worst-case scenario with the intent of putting the proposed optimal aeration profiles to test with the utmost stress. For that reason, the plant is assumed to operate with an influent flow rate of $21.24 \mathrm{MGD}$, and then a storm with a magnitude of 15.85 MGD was introduced.

The storm simulations were realized by combining the nominal influent of the activated sludge tank with the stormwater, which is assumed to be clean and saturated with dissolved oxygen. As a result, the nominal influent is diluted by the oxygen-rich stormwater and the combination is fed as influent to the tank. The dynamic simulations presented in the following sections utilize a simple storm signature; i.e. storms are introduced to the process as a rectangular pulse consisting of a step increase in flow rate, followed by a step decrease. In each of the dynamic simulations, the 
storm was introduced to the system on the $5^{\text {th }}$ day and allowed to last for 2 days. It should be stressed again that this is a highly unlikely scenario that was used only as a worst case.

Before we move on to the comparison of different aeration profiles under storm conditions, it is important to investigate the spatial and temporal phenomena that take place in the activated sludge tank during a storm event. For this reason, we show the results of a storm simulation using the Optimum aeration profile (from Figure 6b) in Figure 10. Figure 10 shows the evolution of the concentration profiles of ammonia and dissolved oxygen in the activated sludge tank as the stormwater is introduced to the process. Also, close-ups showing the first and last few hours of the storm is given at the bottom row.

Until the $5^{\text {th }}$ day, the process is at steady state and the storm is introduced to the process starting from day 5 and removed by day 7 . The disturbance in concentration profiles created by the storm is seen around day 5 in all diagrams (bottom row in Figure 10). In the ammonia diagrams, the red region represents the ammonia peak encountered in the first half of the tank. As seen in the close-ups, this peak region is diluted by the stormwater after day 5 , and the ammonia content of this peak is pushed to the last half of the tank. This effect can be seen to reach the effluent region about 2 hours after the storm starts. However, the increase in ammonia concentration in the effluent region is very small, compared to other regions in the tank. The same effect can also be observed in the dissolved oxygen diagram. Here, we see a great depression in oxygen concentration in the last third of the activated sludge tank to values as low as $1 \mathrm{mg} / \mathrm{L}$. Once again, however, the exit region of the tank experiences less variation owing to the increasing profile of aeration employed in that part of the tank (Figure 6b). Thanks to this aeration configuration, the dissolved oxygen concentration around the effluent does not fall below $6 \mathrm{mg} / \mathrm{L}$ during the storm event.

As the storm ends on the $7^{\text {th }}$ day, a region of recovery can be observed in both diagrams in Figure 10. In the close-up of the ammonia diagram, we see that ammonia concentration across the tank quickly decreases and the peak of ammonia moves back to around the $10^{\text {th }}$ aerator $(\approx 110 \mathrm{~m})$. Likewise, a recovery in dissolved oxygen concentration (specifically in the last half of the tank) is observed. Owing to the diluted concentrations of biomass upon the storm and the oxygen-rich stormwater, the dissolved oxygen concentration reaches above $7 \mathrm{mg} / \mathrm{L}$ across the last half of the activated sludge tank in the first few hours after the storm. This surplus dissolved oxygen helps speed up the recovery of biomass and eventually the operation returns to normal. 
Ammonia Concentration (mg/L)

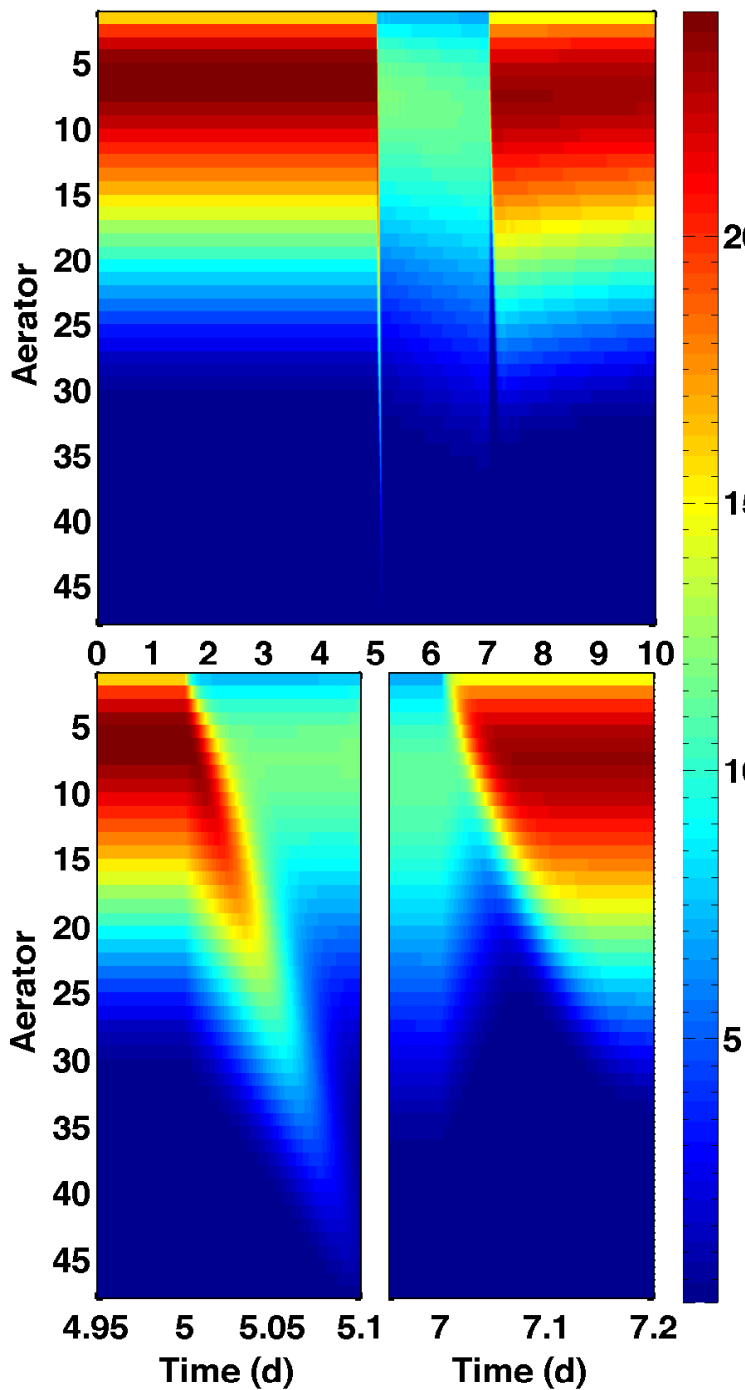

Oxygen Concentration (mg/L)

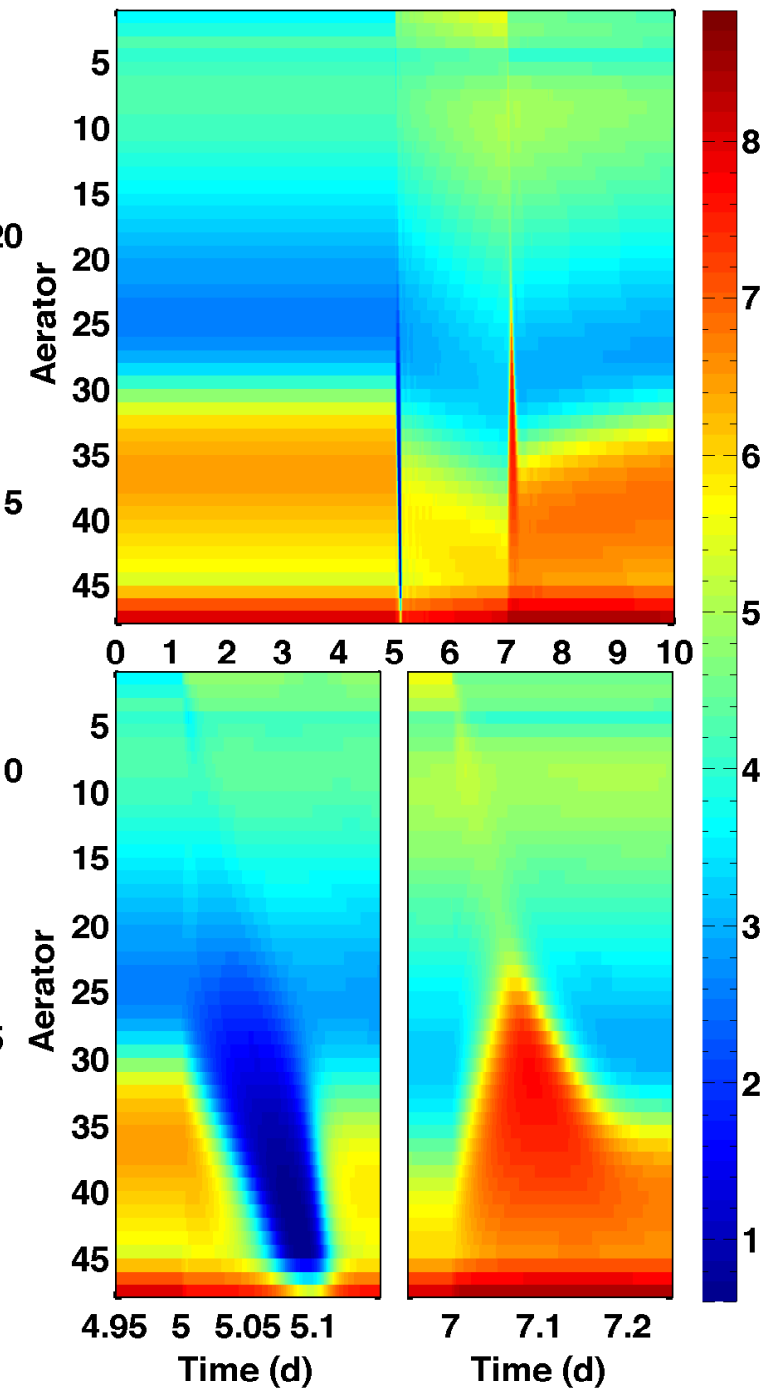

Figure 10: Evolution of concentration profiles of ammonia and dissolved oxygen as the stormwater is introduced to the activated sludge tank, which is operating with the Optimum aeration profile shown in Figure 6. The storm starts on the $5^{\text {th }}$ day and lasts until the $7^{\text {th }}$ day. Pairs of diagrams at the bottom row show the close-ups of the first and last few hours of the storm event, respectively.

The consequences of the storm observed in Figure 10 would become more severe if profiles that are not tailored to the zone-specific oxygen demand are employed. On the other hand, we ideally seek an aeration profile that can endure severe storms and minimize their effects on the effluent quality. In the absence of automatic control, this can be achieved by employing a safety factor over the calculated optimum aeration profiles. In the next section, we compare the storm performances 
of the aeration profiles we have studied so far.

\subsection{Results}

In order to compare performances, four aeration profiles (Nominal, Critical, Optimum and $1.3 \times$ Optimum aeration profiles) were tested with large 2 -day storms. The results of these simulations are given in Figure 11 in terms of effluent concentrations of heterotrophic and autotrophic biomass, dissolved oxygen and ammonia.

When the Nominal aeration profile is utilized, the effect of the storm on effluent concentrations is minimal, mainly because of the excess aeration rate employed throughout the activated sludge tank. Following the increase in flow rate (and the decrease in residence time), the autotrophic and heterotrophic biomass concentrations decrease immediately after the start of the storm. As a result of the decreasing autotrophic biomass population, a small peak emerges in the ammonia diagram right after day 5 , which reaches a concentration of about $0.06 \mathrm{mg} / \mathrm{L}$. Since, at the same time, the dissolved oxygen concentration remains almost constant, the autotroph population can readily oxidize the excess ammonia brought by the peak. However, the ammonia concentration at that point is still above the steady state concentration, and keeps accumulating at a very slow rate due to the reduced autotrophic biomass concentration. Until the storm ends, the concentrations of both biomass species decrease, as the ammonia concentration increases. When the storm is over, on the other hand, both biomass species start recovering and this is followed by a reduction in the effluent ammonia concentration back to the nominal steady state levels.

While the character of dynamic response can be said to be the same for cases with different aeration profiles, the magnitude of the response differs greatly. In the case where the Critical aeration profile is employed, the peak in the ammonia diagram nears a concentration of $0.08 \mathrm{mg} / \mathrm{L}$ within the first hours of the storm. This peak is practically negligible along with the peak observed for the Nominal profile, since the steady state concentration of effluent ammonia is almost the same as the peak values for both profiles. The optimum profile, on the other hand, has an ammonia peak that reaches $0.27 \mathrm{mg} / \mathrm{L}$. While this concentration is well below the NPDES permits given in Table 1, it does violate the default effluent constraint of $0.10 \mathrm{mg} / \mathrm{L}$. Nevertheless, we see that this problem can be readily circumvented when the Optimum aeration profile is increased by $30 \%$. As depicted in Figure 11, the $1.3 \times$ Optimum aeration profile produces the closest response to the Nominal profile in all aspects. In fact, the peak in ammonia reaches $0.06 \mathrm{mg} / \mathrm{L}$ just as it was 
in the Nominal profile. In all cases, the duration of the peak is around 1 hour and dissolved oxygen concentration does not fall below $6.90 \mathrm{mg} / \mathrm{L}$. It is also important to note that none of the ammonia peaks encountered would create a violation of the NPDES permits or the default effluent constraints, if the daily average of the effluent concentrations were calculated. Daily average values of effluent ammonia concentration for the $5^{\text {th }}$ day can be seen in Table 5.1, along with a summary of results for all dynamic simulations.

Table 7: Summary of results for dynamic storm simulations with different aeration profiles.

\begin{tabular}{|c|c|c|c|c|c|}
\hline Case & $\begin{array}{l}\text { Airflow } \\
\text { (MCFD) }\end{array}$ & $\begin{array}{l}\text { Min. } \\
{\left[S_{O}\right]} \\
(\mathbf{m g} / \mathbf{L})\end{array}$ & $\begin{array}{l}\text { Max. } \\
{\left[S_{N H}\right]} \\
(\mathbf{m g} / \mathbf{L})\end{array}$ & $\begin{array}{l}{\left[S_{N H}\right]} \\
\left(5^{t h} \text {-day }\right. \\
\text { ave. }) \\
(\mathbf{m g} / \mathbf{L})\end{array}$ & $\begin{array}{l}\text { Savings } \\
(\%)\end{array}$ \\
\hline Nominal & 17.56 & 9.44 & 0.06 & 0.05 & 0.00 \\
\hline Critical & 7.113 & 8.92 & 0.08 & 0.07 & 59.5 \\
\hline Optimum & 4.970 & 6.92 & 0.26 & 0.09 & 71.7 \\
\hline $1.3 \times$ Optimum & 6.446 & 9.13 & 0.06 & 0.06 & 63.3 \\
\hline
\end{tabular}

For all the aeration profiles given in Table 5.1, except for the Optimum aeration profile, the $5^{\text {th }}$ day average of effluent ammonia concentration is barely different from its steady state value, in spite of a storm that lasts 2 days. This can be better seen by comparing the Nominal and $1.3 \times$ Optimum aeration profiles. It seems that, a $63.3 \%$ reduction in total aeration rate can be accomplished with only a $0.01 \mathrm{mg} / \mathrm{L}$ increase in the daily average effluent ammonia concentration during the storm. Practically, these values could be regarded identical and further indicate a motivation for optimization of aeration profiles in WRPs.

\section{Structured Aeration Profiles}

In the previous sections, we have shown that the optimized aeration profiles provide a great reduction in the aeration burden of the activated sludge process. Implementation of the decreasing and increasing sections of the optimized aeration profiles in a WRP may require an automatic control valve in each aerator. However, many WRPs were built more than 50 years ago and are not equipped with such instruments. As mentioned in Section 2.2, the rate of aeration in the first 


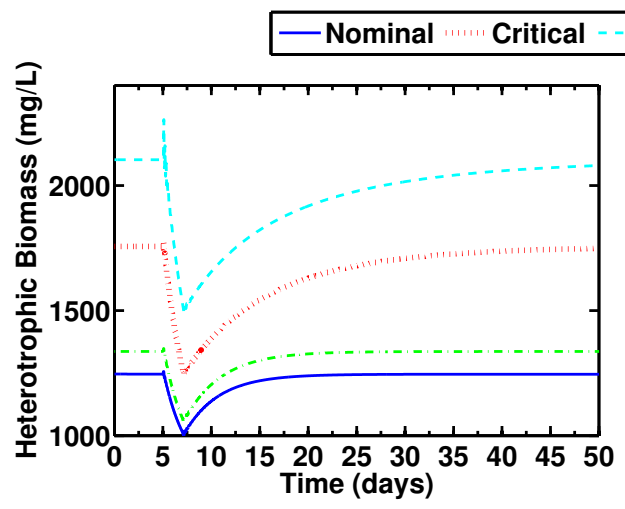

Optimum $-1.3 \times$ Optimum
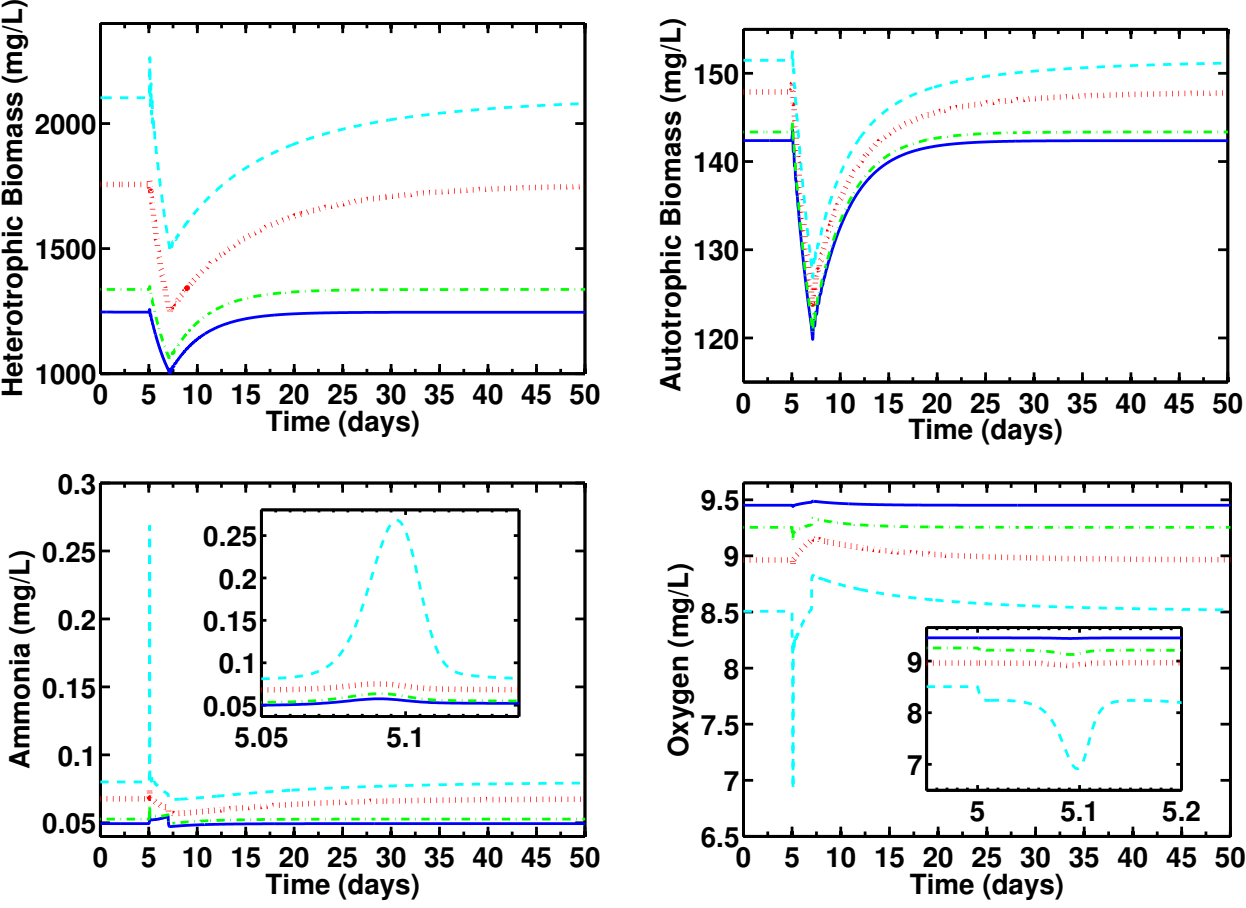

Figure 11: Dynamic response of Nominal, Critical, Optimum and $1.3 \times$ Optimum aeration profiles to a 2-day storm with a size of $60,000 \mathrm{~m}^{3} /$ d. The storm starts on the $5^{\text {th }}$ day and ends on the $7^{\text {th }}$ day.

and last halves of the tank can be controlled via header valves. While the slopes of the decreasing and increasing sections of the aeration profiles cannot be altered through header valves, these valves would still allow the simultaneous manipulation of aeration in a group of aerators effortlessly.

In this section, we propose structured aeration profiles, which would facilitate the manipulation of aeration without requiring sophisticated control equipment. Ideally, this would allow WRPs to try similar approaches toward their efforts in minimization of aeration and energy expenditures. For this purpose, we consider two types of structured profiles: a 2-zone (for activated sludge tanks with two header valves) and a 4-zone structured aeration profiles. The latter profile can either be used in activated sludge tanks with 4 header valves, or it can be utilized in a tank with 2 header valves as a "crude" optimized profile that can be manipulated without the need to calculate aeration values in decreasing or increasing sections. Note that each zone in a structured profile would correspond to a UDA profile.

In this case, the optimized structured profiles were calculated by solving a MINLP problem 
similar to Eq. (5). The pivots are replaced by steps (i.e. equally aerated zones) and aeration rate in each step is allowed to change independently. Therefore, in the 2-zone structured profile, there are 2 optimization variables, representing the aeration rates in the first and second halves of the tank. Similarly, in the 4-zone structured profile, each half of the tank is allowed to have two steps and locations of these steps are determined through optimization with a total of 6 variables.

Figure 12 shows the optimized structured aeration profiles obtained through optimization with 2 and 4 zones, in addition to the Nominal and Optimum aeration profiles. As seen in Figure 12, the structured and Optimum aeration profiles overlap fairly well and provide significant savings compared to the Nominal aeration profile. To be specific, the 2-zone aeration profile results in a total aeration rate of $174,888 \mathrm{~m}^{3} / \mathrm{d}(64.8 \%$ less than nominal), while the 4-zone aeration profile has a much lower aeration rate at $143,071 \mathrm{~m}^{3} / \mathrm{d}(71.2 \%$ less than nominal).

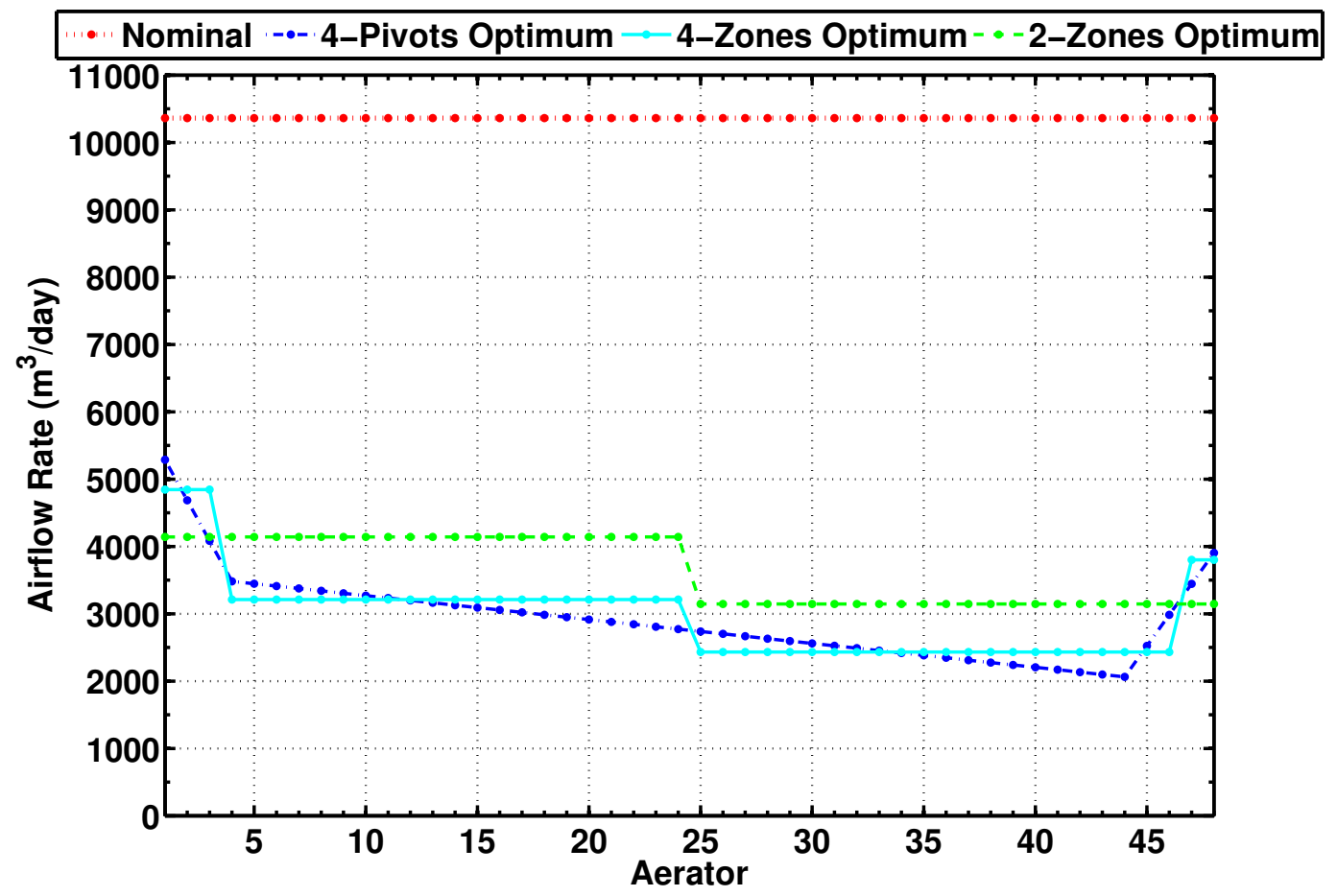

Figure 12: 2-zone and 4-zone Optimum structured aeration profiles, along with the Optimum (Figure 6) and Nominal (Figure 2) aeration profiles.

These figures suggest that the structured profiles can provide aeration savings that are very close to the Optimum aeration profile. In fact, the 4-zone aeration profile provides only $0.5 \%$ 
less savings in aeration compared to the Optimum aeration profile, while the 2-zone profile can save $6.9 \%$ less. This shows that plants can adopt such structured profiles without making a big investment in flow control equipment and can still keep the aeration savings close to optimum.

It is also important to compare the dynamic response of structured profiles with those of the $1.3 \times$ Optimum and Nominal aeration profiles. For this reason, the same storm scenario, which was shown in Figure 11, was simulated using 2- and 4-zone aeration profiles, both of which were increased by 30\%. The results of these simulations are shown in Figure 13.
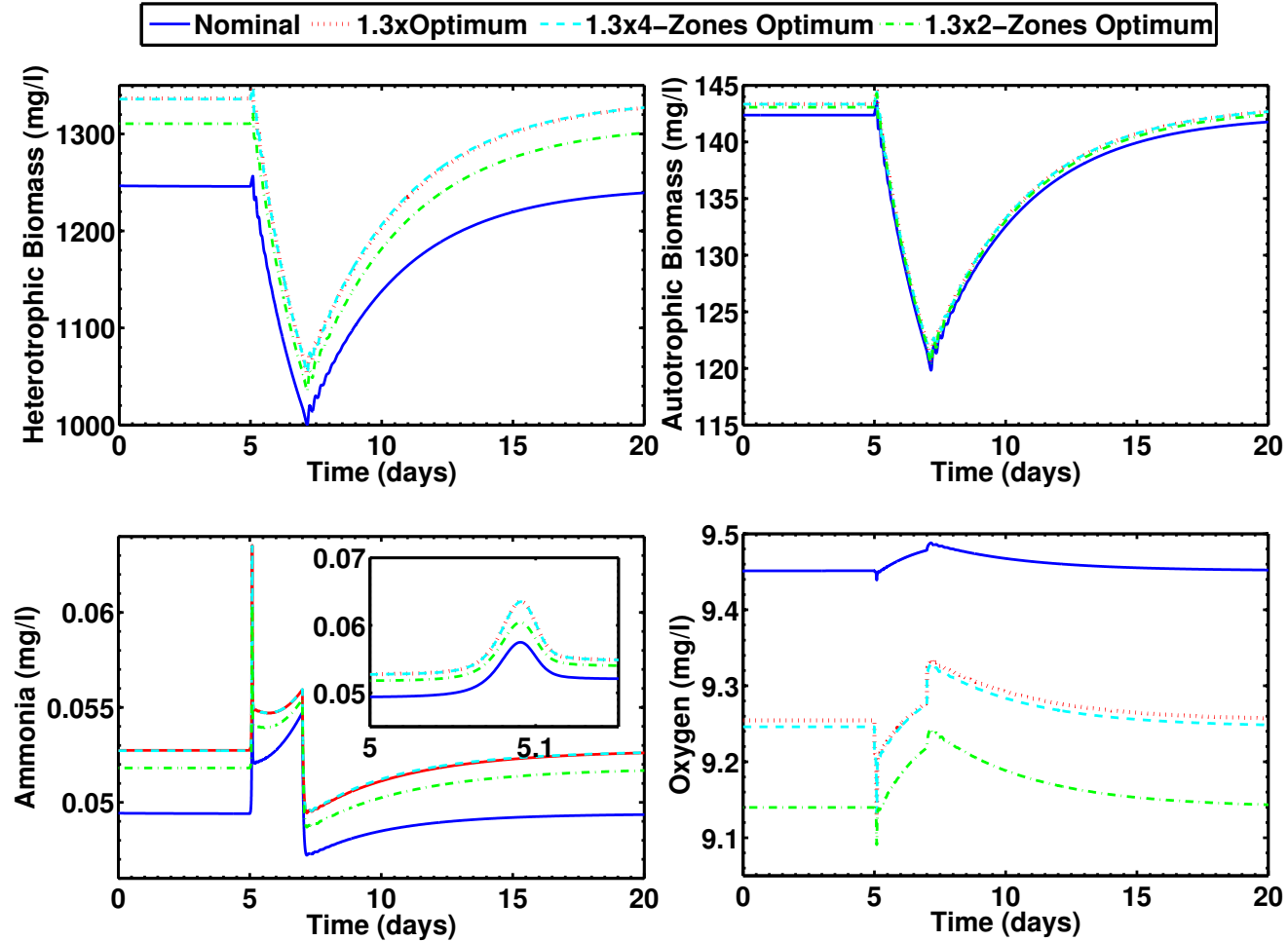

Figure 13: Dynamic response of Nominal, 1.3 $\times$ Optimum and 2- and 4-zone aeration profiles to a 2-day storm with size of $60,000 \mathrm{~m}^{3} / \mathrm{d}$. The storm starts on the $5^{\text {th }}$ day and ends on the $7^{\text {th }}$ day.

As seen in Figure 13, all four aeration profiles exhibit very similar performances against the storm in terms of biomass, ammonia and dissolved oxygen concentrations. Having the highest rate of aeration, the Nominal aeration profile produces the lowest peak in ammonia (around day 5) and the lowest variation in effluent dissolved oxygen concentration. This is followed by the 2-zone aeration profile in terms of effluent ammonia concentration. In fact, one would anticipate this, as this aeration profile uses the second highest aeration rate among the four profiles; however, the 
steady state dissolved oxygen concentration remains the lowest around $9.15 \mathrm{mg} / \mathrm{L}$. Nevertheless, the variation of steady state effluent dissolved oxygen concentration is less then $0.5 \mathrm{mg} / \mathrm{L}$ among all aeration profiles shown, which makes all profiles practically equivalent. The reason behind the relatively low steady state dissolved oxygen concentration observed for the 2-zone aeration profile is its inability to employ an increase in aeration toward the outlet of the activated sludge tank (Figure 12). This further demonstrates the advantage of utilizing NUA profiles in the tank as opposed to a UDA profile.

Finally, we see that the $1.3 \times$ Optimum and the 4 -zone aeration profile (which is also factored by 1.3) exhibit almost identical dynamic responses. Both aeration profiles produce an ammonia peak slightly above $0.06 \mathrm{mg} / \mathrm{L}$ and a dissolved oxygen concentration of $9.25 \mathrm{mg} / \mathrm{L}$. The 1.3 -factored 4-zone aeration profile saves $62.6 \%$ over the Nominal aeration profile and this is only $0.7 \%$ less than the $1.3 \times$ Optimum aeration profile. This justifies the substitution of the 4-zone aeration profile for the $1.3 \times$ Optimum aeration profile, since practically the same storm performance and savings in aeration can be obtained without modification to the airflow control equipment of the plant.

\section{Conclusions}

Steady state optimization results show that there is a great flexibility toward reducing aeration rates in the activated sludge process without any significant changes in the effluent quality. As seen in this work, the use of NUA profiles in the activated sludge tank allows greater savings and robustness compared to UDA profiles. While it is still possible to save on aeration with UDA profiles, the minimization of aeration rates cannot be fully achieved. Therefore, any effort toward optimization of aeration rates in an activated sludge tank should consider and exploit the variable oxygen demand across the tank.

Since the optimal aeration profiles work with the minimum amount of aeration required to carry out the treatment process and meet the constraints, a $30 \%$ increase in these optimal profiles (as a safety factor) can improve the dynamic response of the process toward transient events greatly. Also, 2- or 4-zone aeration profiles that consist of UDA zones can be effectively used in the absence of automatic control valves.

In order to maximize the energy efficiency of the activated sludge process and minimize operational risks, one would ultimately need to implement a robust control scheme on the process. 
A key component of such a control architecture would be optimization, which would ideally be carried out in real-time. However, even with only 6 variables, the optimization procedure requires several hours of computational time and hinders real-time applications.

A good approach to this problem would be an agent-based methodology, which can be reinforced with rule and knowledge bases (such as the historical data from the plant and online or offline bifurcation analyses). Regarding the distributed nature of the system, multiple agents can be employed locally to create a centralized or decentralized cooperative optimization routine. In such a scenario, all 48 local aeration rates can be manipulated based on the dynamic feedback from the process, the historical knowledge and the built-in rule-base. This would also allow commensurate modifications to the optimal aeration profile in accordance with the changing process conditions. A control architecture of this type would likely address challenges such as operational safety and computational time. However, stability and optimality of such an approach needs further investigation.

\section{Acknowledgements}

We would like to thank Prof. Paul Anderson for valuable comments. Also, we acknowledge the feedback and support we received from our collaborators at the Metropolitan Water Reclamation District of Greater Chicago. Lastly, we acknowledge the support from the National Science Foundation under the grant NSF CNS-1035894.

\section{References}

[1] J. Daw, K. Hallett, J. DeWolfe, I. Venner, Energy Efficiency Strategies for Municipal Wastewater Treatment Facilities, Tech. Rep. January, National Renewable Energy Laboratory, Golden, CO (2012).

[2] A. K. R. Ganesan, Mathematical Modeling and Analysis of Wastewater Treatment Processes, M.sc. thesis, Illinois Institute of Technology (2013).

[3] W. F. Owen, Energy in wastewater treatment, Prentice-Hall, Inc., Englewood Cliffs, NJ, 1982. URL http://www.osti.gov/scitech/servlets/purl/5555462

[4] L. Rieger, I. Takács, H. Siegrist, Improving Nutrient Removal While Reducing Energy Use at Three Swiss WWTPs Using Advanced Control, Water Environment Research 84 (2) (2012) 170-188. doi:10.2175/106143011X13233670703684.

URL http://openurl. ingenta.com/content/xref?genre=article\&issn=1061-4303\&volume=84\&issue $=2 \&$ spage $=170$ 
[5] F. Spellman, Handbook of water and wastewater treatment plant operations, CRC Press, 2008.

URL http://books.google.com/books?hl=en\&lr=\&id=Ja28hvTxVpwC\&oi=fnd\&pg=PR35\&dq=handbook+of+ water+and+wastewater+treatment+plant+operations\&ots=wz2ijs4ufZ\&sig=QNpf 5 CC1buRqEj3sVUCil-7NXz0

[6] M. C. Ozturk, F. Teymour, Bifurcation Analysis of Wastewater Treatment Processes, Industrial \& Engineering Chemistry Research 53 (45) (2014) 17736-17752. doi:10.1021/ie502583q.

URL http://pubs.acs.org/doi/abs/10.1021/ie502583q

[7] B. Chachuat, N. Roche, M. Latifi, Dynamic optimisation of small size wastewater treatment plants including nitrification and denitrification processes, Computer Aided Chemical Engineering 8 (2000) 853-858. doi:10. 1016/S1570-7946(00)80144-3.

[8] B. Chachuat, N. Roche, M. Latifi, Optimal aeration control of industrial alternating activated sludge plants, Biochemical Engineering Journal 23 (2005) 277-289. doi:10.1016/j.bej.2005.01.012.

[9] M. Fikar, B. Chachuat, M. Latifi, Optimal operation of alternating activated sludge processes, Control Engineering Practice 13 (2005) 853-861. doi:10.1016/j.conengprac.2004.10.003.

[10] L. A mand, B. Carlsson, Optimal aeration control in a nitrifying activated sludge process, Water Research 46 (2012) 2101-2110. doi:10.1016/j.watres.2012.01.023.

[11] R. Piotrowski, M. a. Brdys, K. Konarczak, K. Duzinkiewicz, W. Chotkowski, Hierarchical dissolved oxygen control for activated sludge processes, Control Engineering Practice 16 (2008) 114-131. doi:10.1016/ j.conengprac. 2007.04 .005 .

[12] S. R. Weijers, Modelling, identification and control of activated sludge plants for nitrogen removal, Ph.D. thesis, Technische Universiteit Eindhoven Veldhoven, The Netherlands (2000).

[13] P. Ingildsen, Realising full-scale control in wastewater treatment systems using in situ nutrient sensors, Ph.d. thesis, University of Lund, Sweeden (2002).

[14] R. Hill, R. Manross, E. Davidson, T. Palmer, M. Ross, S. Nutt, Sensing and Control Systems: A review of municipal and industrial experiences, IWA Publishing, Alexandria, VA, 2002.

[15] U. Jeppsson, J. Alex, M. N. Pons, H. Spanjers, P. A. Vanrolleghem, Status and future trends of ICA in wastewater treatment- a European perspective, Water Science \& Technology 45 (4-5) (2002) 485-494.

[16] M. Henze, C. P. L. Grady Jr, W. Gujer, G. Marais, T. Matsuo, Activated Sludge Model No. 1, in: IAWPRC Scientific and Technical Report No. 1, IWA Publishings, London, 1987.

[17] M. Henze, Activated sludge models ASM1, ASM2, ASM2d and ASM3, no. 9, IWA Publishing, 2000.

[18] A. J. Chipperfield, P. J. Fleming, The MATLAB Genetic Algorithm Toolbox, in: IEE Colloquium on Applied Control Techniques Using MATLAB, Vol. 1995, IET, 1995, pp. 10/1-10/4. doi:10.1049/ic:19950061.

URL http://digital-library.theiet.org/content/conferences/10.1049/ic_19950061

[19] D. Whitley, A genetic algorithm tutorial, Statistics and Computing 4 (2) (1994) 65-85. doi:10.1007/ BF00175354

URL http://link.springer.com/10.1007/BF00175354 